\title{
La reparación del incumplimiento del plazo razonable en el Tribunal de Justicia de la Unión Europea y una posible consecuencia para el estatus de los derechos fundamentales*
}

Edorta Cobreros Mendazona

DOI: https://doi.org/10.47623/ivap-rvap.109.2017.1.01

\begin{abstract}
Sumario: I. Introducción.-II. La inicial solución "endoprocesal» adoptada en la Sentencia Baustahlgewebe c. Comisión: 1. Solicitud de compensación por las dilaciones indebidas constatadas en un proceso ante el Tribunal de Primera Instancia. 2. La propuesta del Abogado General del remedio a través de la acción de indemnización. 3. La solución adoptada por la S. Baustahlgewebe c. Comisión: rebaja la sanción fijada en la sentencia recurrida.-III. Evolución de los pronunciamientos posteriores en relación con el plazo razonable: 1. Continuidad con Baustahlgewebe. 2. Primeros distanciamientos.-IV. La posterior y definitiva interpretación que remite a la vía del recurso de indemnización: 1. El punto de inflexión: las sentencias Gascogne Sack Deutschland c. Comisión y otras. 2. Otros pronunciamientos que ratifican esta interpretación. $-V$. Aplicación efectiva del recurso de indemnización en el caso de dilaciones indebidas: 1. Primeras sentencias. 2. Sentencias posteriores. 3. Algunas consideraciones sobre esta nueva vía compensatoria.-VI. Una consecuencia de gran alcance: la lesión del derecho fundamental al plazo razonable constituye una violación suficientemente caracterizada del Derecho de la Unión Europea a efectos de responsabilidad patrimonial: 1. La violación suficientemente caracterizada del Derecho de la Unión como requisito para la indemnización. 2. El incumplimiento del plazo razonable como violación suficientemente caracterizada del Derecho de la Unión Europea. - VII. Una (posible) deducción más general: la conculcación de un derecho fundamental constituye per se una violación suficientemente caracterizada del ordenamiento de la Unión.-VIII. Conclusiones finales de este largo proceso.
\end{abstract}

\footnotetext{
* Trabajo realizado para el merecido homenaje a Luciano Parejo Alfonso. Excelente universitario y mejor persona, el prof. Parejo siempre ha desarrollado sus numerosas tareas en el servicio público con gran responsabilidad; somos muchos los que apreciamos, además, su afabilidad y ausencia de engreimiento.
} 


\section{Introducción}

Está muy extendida y es recurrente la preocupación por unos procesos judiciales que se lleven a cabo en un tiempo "útil». En este sentido, la aplicación judicial del Derecho sin retrasos no es un problema reciente sino que viene de lejos. Acotada en sus comienzos al ámbito de la jurisdicción penal(1), la necesidad de atajar el retraso en todos los ámbitos jurisdiccionales resultará, sin embargo, cada vez más patente. Conocida es, así, la rotunda proclamación que, en su comienzo, efectúa el decisivo art. 6.1 del Convenio para la Protección de los Derechos Humanos y de las Libertades Fundamentales de 1950: "Toda persona tiene derecho a que su causa sea oída equitativa, públicamente y dentro de un plazo razonable, por un Tribunal independiente e imparcial, establecido por la Ley, que decidirá los litigios sobre sus derechos y obligaciones de carácter civil o sobre el fundamento de cualquier acusación en materia penal dirigida contra ella». Texto del que, además de otras importantes particularidades, destaca que no se refiere sólo a los procesos penales, sino también, expresamente, a los litigios sobre derechos y obligaciones de carácter civil (2).

En el ámbito de la Unión Europea - que es el que más directamente interesa en este trabajo-, la Carta de los Derechos Fundamentales de la Unión Europea (formulada como "Carta de Niza» en 2000 e introducida como Derecho originario vinculante a partir del art. 6 TUE, con el Tratado de Lisboa en diciembre de 2009) establece también, en su art. 47 (que encabeza su Título VI, "Justicia»), el derecho de toda persona a que su causa sea oída "en un plazo razonable».

A estos nudos datos normativos conviene añadir que las preocupaciones al respecto se orientan en una triple dirección: a) cómo evitar, en el seno de un proceso, que se produzcan dilaciones indebidas, y que se traducirá, en su caso, en la existencia de mecanismos (normalmente procesales) a los que acudir cuando exista tal riesgo y que pudieran impedir su

(1) Baste ahora con recordar, por ejemplo, el capítulo dedicado en 1764 a la "Prontitud de la pena" por el Marqués de BECCARIA [De los delitos y de las penas. (Prefacio y notas de P. Calamandrei. Traducción de S. Sentís Melendo y M. Ayerre Redín). Ediciones Jurídicas Europa-América. Buenos Aires, 1974, págs. 152-155]; o la VI Enmienda a la Constitución Americana, de 1791, para proclamar que «en toda causa criminal el acusado gozará del derecho a ser juzgado rápidamente y en público por un jurado imparcial» (el conocido right to speedy and public trial).

Más cercano en el tiempo, y enmarcado ya en la protección internacional de los derecho fundamentales, tenemos el art. 14.3,c) del Pacto Internacional de Derechos Civiles y Políticos, de 1966, que proclama - con expresión que, años más tarde, se nos hará propia- que, durante el proceso, toda persona acusada de un delito tiene derecho «a ser juzgada sin dilaciones indebidas».

(2) En la interpretación amplia - conviene añadir- de que ha sido objeto por la jurisprudencia europea esta exigencia del carácter civil de los derechos o las obligaciones judicialmente reclamados. 
consumación; b) cómo reparar los supuestos en los que ya se ha producido, efectivamente, el indebido retraso; y c) en una línea más reciente y proactiva, cómo establecer mecanismos que garanticen unos tiempos óptimos de desarrollo de los procesos y una previsibilidad de su desarrollo temporal (3).

Aquí vamos a ocuparnos de la segunda de las vertientes - la reparadora-, acotándola al ámbito de actuación delTribunal de Luxemburgo. El interés de este análisis radica no sólo en la importancia del sujeto y en el amplio ámbito de su eficacia sino también en que su construcción no ha sido ni lineal ni monolítica llegando hasta nuestros días los intentos (jurisprudenciales) de su definición, lo que demuestra las dificultades que tienen los mecanismos compensatorios cuando se refieren a las más altas instancias jurisdiccionales. En efecto, hace casi veinte años el Tribunal de Justicia (entonces, de las Comunidades Europeas) dictó su primera resolución al respecto. Con posterioridad, se ha producido un notable cambio en su interpretación que ha empezado a materializarse (y no sin resistencias) este año 2017.

Pero, además de las claves de este proceso evolutivo, que se ha extendido en el tiempo hasta nuestros días, veremos también que quizá se puede originar una consecuencia de largo alcance para el ordenamiento de la Unión Europea - más concretamente, para la posición de los derechos fundamentales en dicho ordenamiento- y que la construcción jurisprudencial objeto de análisis ha desvelado, como es que su conculcación -la de los derechos recogida en la Carta de los Derecho Fundamentales de la Unión Europea- pueda considerarse, con las cautelas que se dirán, una "violación suficientemente caracterizada" del Derecho de la Unión a efectos de su reparación patrimonial.

Ambos aspectos se desarrollarán a continuación, con el inevitable detenimiento y el necesario matiz que requieren la novedad y el calado de alguna de las cuestiones puestas de manifiesto.

(3) Respecto de los dos primeros aspectos, y en relación con la exigencia de que los Estados tengan un recurso nacional de reparación de una eventual lesión del derecho al plazo razonable que pueda considerarse un recurso «nacional efectivo (ex art. $13 \mathrm{CEDH}$ ), pueden tener interés las consideraciones efectuadas en la reciente STEDH de 24 de enero de 2017, as. Hiernaux c. Bélgica, núm. 28022/15, aptdos. 45 a 48, donde se recuerda su jurisprudencia consistente en que los Estados gozan de un margen de apreciación a la hora de asumir los remedios contra tales violaciones del derecho al plazo razonable del art. 6.1 CEDH, pudiendo tratarse tanto de recursos preventivos como indemnizatorios.

En referencia al tercer aspecto, debemos mencionar los trabajos desarrollados por la Comisión Europea Para la Eficacia de la Justicia (más conocida como CEPEJ, http://www.coe.int/t/dghl/cooperation/cepej/default_en.asp), creada en el seno del Consejo de Europa por Resolución del Comité de Ministros de 18 de septiembre de 2002 [Resolución (2002)12]. 


\section{La inicial solución "endoprocesal» adoptada en la Sentencia Baustahlgewebe c. Comisión}

\section{Solicitud de compensación por las dilaciones indebidas constatadas en un proceso ante el Tribunal de Primera Instancia}

La primera vez que el Tribunal de Luxemburgo se enfrenta con el problema de la conculcación del plazo razonable en su propia jurisdicción tiene lugar en la conocida Sentencia Baustahlgewebe c. Comisión(4). Sintéticamente planteado, el asunto fue el siguiente.

La Comisión impuso unas multas a una serie de empresas por prácticas colusorias de la competencia; más concretamente, una de 4,5 millones de ecus a la empresa alemana que da nombre a este asunto. Ésta planteó, inicialmente, un recurso de anulación ante el (entonces) Tribunal de Primera Instancia, que resolvió en su sentencia mantener la multa (aunque reduciendo su importe a 3 millones de ecus) (5).

Contra esta resolución judicial, la empresa recurrió ante el Tribunal de Justicia. Su recurso de casación lo fundamentó en seis motivos, el primero de los cuales era, precisamente, la conculcación del plazo razonable, por la excesiva duración del proceso judicial a quo -casi cinco años y medio, de los que cerca de veintidós meses se dedicaron a deliberaciones-, con mención expresa del art. 6.1 del Convenio Europeo de protección de los Derechos Humanos.

Por esta razón la recurrente entendía que debía anularse la Decisión sancionadora de la Comisión, solicitando subsidiariamente que se minorase su cuantía. Éstos eran, pues, los términos en los que se planteaba el asunto ante elTribunal de Justicia.

(4) Sentencia de 17 de diciembre de 1998, C-185/95P, sobre cuya importancia me pareció pertinente llamar la atención en su momento: vid. COBREROS MENDAZONA, E., "Las dilaciones indebidas en los procesos judiciales. Un problema generalizado y de no fácil solución", en RVAP núm. 58 (II), 2000, espec. págs. 181 y 182; y de la que me ocupé con detenimiento en «Violación del plazo razonable en el Tribunal de Justicia de la Unión Europea: su compensación y dos consecuencias importantes", en RVAP núm. especial 99/100, 2014, vol. I, espec. págs. 923-927 (trabajo del que aquí se parte y completa). También se ha ocupado de esta sentencia MOREIRO, C.J., en La invocación del plazo razonable ante el Tribunal de Justicia. Dykinson. Madrid, 2012, págs. 76 y ss.

Con bastante anterioridad a su inclusión en 2010 como atenuante en el vigente art. 21.6 del Código Penal, esta sentencia fue aducida por la Sala de lo Penal del Tribunal Supremo en sus iniciales intentos de "remediar" las dilaciones indebidas en el proceso penal por la vía, ex analogia, de una atenuante modificativa de la responsabilidad criminal. Vid. la STS (2. ${ }^{\mathrm{a}}$ ) de 8 de junio de 1999, rec. núm. 1731/1998, ponente Bacigalupo.

(5) Sentencia Baustahlgewebe c. Comisión, de 6 de abril de 1995, T-145/89. 


\section{La propuesta del Abogado General del remedio a través de la acción de indemnización}

Tiene interés, por lo que luego se verá, analizar la interpretación propuesta por el Abogado General Léger en sus Conclusiones(6), que - se adelanta ya - no será la que luego siga la sentencia, aunque sí la que se impondrá años más tarde.

Desde un comienzo pone de relieve la importancia que tiene, de todos los motivos esgrimidos, el basado en la inobservancia del plazo razonable y, además, plantea las tres posibilidades que, en hipótesis, le caben al Tribunal de Justicia al resolver un recurso de casación de este tipo: a) anular la multa, b) reducirla o, c) si no dispone de elementos suficientes, devolver el asunto al Tribunal de Primera Instancia.

Descartada esta última posibilidad, por razones obvias, el Abogado General examina las soluciones arbitradas en los ordenamientos jurídicos de los Estados, para ver si existe una "tradición jurídica común» en la que pudiera inspirarse el Tribunal de Justicia, Ilegando a la conclusión de que existen soluciones diversas, aunque - señala - en la mayoría de ellos la constatación de la vulneración del plazo razonable "carece de incidencia en la validez de los procedimientos de que se trata. Tan sólo permite interponer ante el órgano jurisdiccional competente un recurso de indemnización» (7).

En este mismo sentido, considerará que la solución más compartida entre los Estados miembros, para resolver los casos de inobservancia del plazo razonable, es el reconocimiento al justiciable de un derecho a ser indemnizado; a lo que añade que la vía consistente en repercutir sobre la sanción penal no le parece una solución adecuada. En efecto, para el Abogado General, será la aplicación errónea del Derecho por parte delTribunal de Primera Instancia la que le confiere al Tribunal de Justicia la facultad de anular, total o parcialmente, la sentencia recurrida (y, así, suprimir o reducir la multa impuesta); pero no era ése el caso, claramente (8).

En tales circunstancias, a juicio del Abogado General, no hay relación entre la falta de respeto del plazo razonable y un nuevo examen de la cuestión de fondo - esto es, de la legalidad de la multa impuesta por la

(6) Presentadas el 3 de febrero de 1998. De manera puramente incidental (porque la referencia se hacía a un aspecto que aquí no interesa), podemos señalar que estas Conclusiones fueron mencionadas por nuestro Tribunal Constitucional en su Auto de planteamiento de la primera cuestión prejudicial ante elTribunal de Luxemburgo (vid. ATC núm. 86/2011, de 9 de junio, FJ 6).

(7) Aptdo. 53 de las Conclusiones cit. (la cursiva aparece en el original).

(8) Ya que, por mucho que sea el tiempo dedicado por el Tribunal de Primera Instancia a examinar la legalidad de la Decisión recurrida, no afecta ni a la comprobación de los hechos imputados ni a la apreciación de su responsabilidad en las prácticas indebidas, ni a la aplicación efectuada del Derecho comunitario aplicable ( vid. aptdo. 58 de las Conclusiones cit.). 
Comisión-, y tal «inexistencia de relación se opone a que este Tribunal se atribuya el derecho, a falta de una disposición que le autorice expresamente para ello, de basarse en el incumplimiento del "plazo razonable" para reducir o anular, mediante la revocación de la sentencia impugnada, la multa» (9). Además, la lógica de la compensación, significaría deducir de una pena la cuantía de una reparación, lo que no deja de ser algo extraño.

Por todas esas razones, el Abogado General concluirá que el motivo no puede prosperar, proponiendo al Tribunal de Justica que lo desestime sin ulterior examen (10). Ahora bien, esta respuesta le parece insuficiente y dedica también una parte destacada de sus Conclusiones a la alternativa que propone, que no es sino el ejercicio de la acción de indemnización(11).

A estos efectos, la primera dificultad que hay que soslayar es que la competencia para conocer de las acciones de indemnización contra una Institución de la Unión Europea está atribuida, precisamente, al propioTribunal General (entonces Tribunal de Primera Instancia) (12). Pero, como esto iría en contra del principio de imparcialidad (que se opone a que sea el propio órgano jurisdiccional el que aprecie y enjuicie su comportamiento), una interpretación pro justiciable exigiría - en su opinión- que se completasen las previsiones normativas sobre los asuntos de que conoce el Tribunal de Justicia, considerando que también tiene atribuida la competencia para conocer de las reclamaciones indemnizatorias imputables alTribunal de Primera Instancia (13).

Así, pues, para el Abogado General, la solución no está en minorar o anular la multa (es decir, "aprovechar» el recurso de casación para intentar garantizar la eficacia del art. $6.1 \mathrm{CEDH}$ ), sino en reenviar a la afectada a un recurso de indemnización, aunque ante el Tribunal de Justicia y no

(9) Aptdo. 59 de las Conclusiones cit. (la cursiva está añadida).

(10) Aptdo. 61 de las Conclusiones cit.

(11) «Dado que el recurso de casación no constituye un respuesta válida a la efectividad del "plazo razonable", soy del parecer de que ha de buscarse en la acción indemnizatoria el medio para evitar que dicho principio del Convenio no pase de ser letra muerta cuando se invoca contra un procedimiento ante el Tribunal de Primera Instancia» (aptdo. 63 de las Conclusiones cit.).

(12) Para valorar debidamente lo propuesto por el Abogado General, adviértase que, en el momento de emitirse estas Conclusiones, las competencias del Tribunal de Primera Instancia venían establecidas por la Decisión 88/951 del Consejo, modificada por la Decisión 93/350 CECA, CEE y Euratom. Posteriormente ya lo serán por Derecho originario: en la actualidad es el art. 256 TFUE el decisivo.

(13) Concluyendo así: «Procede, por tanto, tal y como le autoriza a este Tribunal el párrafo segundo del artículo [340TFUE], inspirarse en esta tradición común para reconocer una forma idéntica de resolución de los litigios [refiriéndose a la de los ordenamientos de los Estados] que venga a completar, en el área que le corresponde, el ámbito abarcado por el recurso de casación. Se trata, pues, tan sólo de suplir las insuficiencias de este recurso para dar respuesta a un motivo específico en un ámbito que, por lo demás, se aproxima más al del funcionamiento de la justicia que al del ejercicio de la actividad jurisdiccional» (aptdo. 74 de las Conclusiones cit.). 
ante el propio Tribunal de Primera Instancia(14). Vemos, pues, cómo se plantea la "clásica" discusión sobre el acierto de la compensación por las dilaciones indebidas en el seno del mismo proceso en que tuvieron lugar (en forma de minoración o incluso eliminación de la medida punitiva discutida) o en otro proceso distinto (con la lógica puramente indemnizatoria del perjuicio causado).

Debe destacarse, asimismo, que el Abogado General menciona expresamente el sistema de responsabilidad extracontractual de las Instituciones de la Comunidad, infiriéndose, así, una admisión de la responsabilidad extracontractual del Tribunal de Justicia de las Comunidades Europeas. Lo que, en ese momento, constituye, ciertamente, un aspecto novedoso (15).

Como se ha adelantado, esta tesis no será la que prospere en aquel momento, pero sí la que (con algún matiz) acabe imponiéndose.

\section{La solución adoptada por la Sentencia Baustahlgewebe c. Comisión: rebaja de la sanción fijada en la sentencia recurrida}

Tras una referencia al art. 6.1 CEDH, la primera y rotunda afirmación que se contiene en esta sentencia - que ya se ha señalado que se dicta en recurso de casación contra la dictada previamente por el Tribunal de Primera Instancia en un recurso de anulación - es que «el principio general del Derecho comunitario», según el cual toda persona tiene derecho a un juicio justo, es un principio que se inspira en los derechos fundamentales garantizados por el Convenio de Roma(16); y, más

(14) Vid. los aptdos. 71 y 72 de las Conclusiones cit.

(15) En la doctrina había muy pocas referencias a esta posibilidad, ciertamente. Una de ellas aparece mencionada en las propias Conclusiones (nota 32), y es el trabajo de DU BAN, B., "Les principes generaux communs et la responsabilité non contractuelle de la Communauté», en Cahiers de droit européen, núm. 4, 1977, espec. págs. 403 y ss.; pero que se refiere únicamente a la hipótesis de lo que -con nuestras categorías - Ilamaríamos "error judicial», mas no al caso de un "funcionamiento anormal de la Administración de Justicia».

(16) Repárese en que, en el momento en el que se hace esta afirmación (1998) nos encontramos en la fase evolutiva del ordenamiento comunitario de exclusiva (y acertada, aunque insuficiente) creación jurisprudencial, a efectos de la aplicación de los derechos fundamentales, incluida su inspiración en el Convenio Europeo y en la propia jurisprudencia de Estrasburgo (como se hace meridianamente en esta sentencia). Fase bastante lejana aún en el tiempo de los tres apartados del actual art. 6 TUE.

Desde la otra vertiente, el Tribunal Europeo de Derechos Humanos mencionará más tarde esta $S$. Baustahlgewebe c. Comisión, para referirse a la atención prestada por el Tribunal de Luxemburgo a la jurisprudencia del Tribunal de Estrasburgo (al enjuiciar el célebre caso Bosphorus, Sentencia de 30 de junio de 2005, as. $45036 / 98$, en la nota 8 , donde se planteaba, precisamente, el posible control por aquél de las actuaciones de los Estados cuando ejecutaban el Derecho comunitario). E incluso (aunque por referencia indirecta) para referirse precisamente al derecho a un proceso sin dilaciones indebidas en su STEDH de 23 de mayo de 2016, caso Avotins c. Letonia, núm. 17502/07, aptdo. 41. 
concretamente, que el plazo razonable es aplicable en el marco de un recurso jurisdiccional contra una Decisión de la Comisión por la que se impone a un empresa una multa por violación del Derecho de la competencia (17).

Para analizar, entonces, si se había respetado este principio del plazo razonable por parte del Tribunal de Primera Instancia, el Tribunal de Justicia utiliza los mismos criterios, conocidos y ya clásicos, del Tribunal Europeo de Derechos Humanos cuando aplica aquél artículo(18): la trascendencia del asunto para la afectada, la complejidad del pleito, la propia conducta de la recurrente $y$, finalmente, el comportamiento, en el caso, delTribunal de Primera Instancia.

A la vista de las circunstancias, la sentencia considerará, textualmente, que «es preciso reconocer que, aun teniendo en cuenta la relativa complejidad del asunto, el procedimiento ante el Tribunal de Primera Instancia rebasó las exigencias relacionadas con el respeto del plazo razonable» (aptdo. 47).

En escueta argumentación de la propia sentencia $-y$ apartándose de la propuesta ya considerada del Abogado General-, la consecuencia será la siguiente: "Por razones de economía procesal y para garantizar una protección inmediata y efectiva contra dicha irregularidad del procedimiento, debe declararse que el motivo referente a la duración excesiva del procedimiento es fundado" (aptdo. 48). Ésa es, pues, la razón para estimar el recurso.

Ahora bien, "a falta de cualquier indicio de que la duración del procedimiento haya tenido alguna incidencia en la solución del litigio", no procederá la anulación de la totalidad de la sentencia (aptdo. 49). Y, entonces, el Tribunal de Justicia considerará que la cantidad de cincuenta mil ecus «constituye una compensación equitativa, en razón de la excesiva duración del procedimiento" (aptdo. 141), razón por la cual reduce la multa a 2.950.000 ecus (aptdo. 142). Debemos Ilamar la atención sobre la primera razón - si el retraso no incide en la solución que se debía haber adoptado en Derecho, no se debe anular en casación la sentencia recurrida en su totalidad; pero sí en parte, como vemos que hace esta Sentencia(19) - , porque en este punto radicará buena parte de la argumentación que acabará llevando al Tribunal a cambiar su jurisprudencia.

(17) Como era el caso (aptdo. 21 de la S. Baustahlgewebe c. Comisión cit.).

(18) Si bien remitiéndose a sus sentencias "por analogía» (S. Baustahlgewebe c. Comisión cit., aptdo. 29).

(19) En contra del criterio del Abogado General, que ya conocemos (vid. supra aptdo. II.2). 
Y también hay que subrayar que la sentencia adopta esta solución, como ya se ha recogido, para otorgar una "compensación" por el retraso.

Vemos pues que, para dar una solución más efectiva, el Tribunal de Justicia reduce la multa establecida en la sentencia recurrida(20) a efectos, se insiste, de compensación y, por tanto, con la misma ratio de una indemnización. Pero lo hace dentro del propio proceso en vía de recurso(21); sin reenviar, por tanto, a un nuevo proceso indemnizatorio, que era lo propuesto por el Abogado General. Adviértase que, si bien se habla de una "compensación equitativa» (22), no hay mención expresa alguna en la sentencia a una posible responsabilidad extracontractual del Tribunal de Justicia de la Unión Europea, como sí la había en la Conclusiones del Abogado General -y que, en definitiva, sería el fundamento de tal compensación indemnizatoria-; ni, por lo tanto, tampoco referencia alguna a los requisitos jurisprudenciales acuñados para aplicar las previsiones del (actual) art. 340 TFUE.

\section{Evolución de los pronunciamientos posteriores en relación con el plazo razonable}

Tras la sentencia anterior, el Tribunal de Justicia se pronunciará en diversas ocasiones sobre la violación del plazo razonable en vía jurisdiccional y sus consecuencias, lo que repasamos sumariamente a continuación, destacando el iter interpretativo seguido.

\section{Continuidad con Baustahlgewebe}

Podemos agrupar en este apartado cuatro sentencias - que abarcan un periodo de siete años (de 2002 a 2009) - que tienen en común que el Tribunal de Justicia ratifica expresamente en todas ellas su construcción Baustahlgewebe, pero en las que no se reconoce la existencia de violación del plazo razonable en los respectivos procesos judiciales seguidos ante el Tribunal General y, por lo tanto, no tienen que "compensar» daño alguno. Se trata de las siguientes sentencias:

(20) Que, a su vez, ya había reducido algo el Tribunal de Primera Instancia en el recurso de anulación judicial, como se ha mencionado.

(21) De ahí la calificación de solución «endoprocesal» que hemos utilizado para designar esta primera interpretación delTribunal de Luxemburgo.

(22) Lo que recuerda no poco a la "satisfacción equitativa», prevista en el art. $41 \mathrm{CEDH}$, a efectos de la completa reparación de la violación de un derecho protegido por el Convenio. 

A) Sentencia LVM y otros c. Comisión(23).
B) Sentencia Corus c. Comisión(24).
C) Sentencia Sumitomo y Nippon c. Comisión(25).
D) Sentencia Paperfabrik y otros c. Comisión(26).

\title{
2. Primeros distanciamientos
}

\author{
En 2008 y 2009 se pueden detectar ya los primeros pronunciamientos \\ que marcan, claramente, distancia con la solución Baustahlgewebe. Me- \\ rece referir con algún detenimiento las sentencias principales.
}

(23) De 15 de octubre de 2002, asuntos acumulados C-238/99P, C-244/99P, C-245/99P, C-247/99P, C-250/99P, C-252/99P y C-254/99P, dictada también en vía casacional contra una sentencia dictada en recurso de anulación contra una serie de decisiones de la Comisión en el marco del Derecho de la competencia.

Contiene esta sentencia una interpretación -en la que el Tribunal de Justicia insistirá en posteriores ocasiones - consistente en considerar que la lista de estos criterios no es exhaustiva y que la apreciación de la razonabilidad del plazo no requiere un examen sistemático de todas las circunstancias del asunto en función de cada uno de ellos cuando la duración se revela justificada en función de uno solo; y que, a la inversa, también puede considerarse que un lapso de tiempo sobrepasa los límites admisibles en función de uno solo de los criterios. Esta interpretación la efectúa al analizar los conocidos criterios con respecto al procedimiento administrativo seguido por la Comisión y no al tratar del proceso judicial seguido ante el Tribunal de Primera Instancia (aptdo. 188).

Además, esta sentencia ofrece una consideración adicional que puede ser representativa de su forma de ver las cosas a este respecto: «es preciso subrayar que el deseo de celeridad que debe animar a la Comisión, en la fase de la investigación, y al órgano jurisdiccional comunitario, en la fase de los procedimientos jurisdiccionales, no debe menoscabar los esfuerzos realizados por cada institución para aclarar plenamente los hechos controvertidos, ofrecer a las partes afectadas todas las facilidades para presentar sus pruebas y sus observaciones y para pronunciarse únicamente tras una madura reflexión sobre la existencia de las infracciones y las sanciones» (aptdo. 234).

(24) De 2 de octubre de 2003, asunto C-199/99P. Dictada también en relación con una multa impuesta por la Comisión en el ámbito del Derecho de la competencia, el Tribunal de Justicia no admite el motivo basado en la excesiva duración del proceso (casi cinco años) ante el Tribunal de Primera Instancia - con cita expresa de la $S$. Baustahlgewebe-, debido a la complejidad del proceso (con numerosas partes, cuatro lenguas de procedimiento y diversas cuestiones jurídicas planteadas en relación con el acceso a la documentación).

(25) De 25 de enero de 2007, asuntos acumulados C-403/04P y C-405/04P. Asimismo en relación con una multa impuesta por la Comisión por prácticas colusorias de la competencia. En el recurso de casación se alega la excesiva duración del proceso de anulación ante el Tribunal de Primera Instancia (cuatro años y tres meses). La sentencia recuerda Baustahlgewebe y concluye que no ha habido vulneración del plazo razonable.

Repárese en que esta sentencia "continuista» es posterior en el tiempo a las dos primeras sentencias que se mencionan en el apartado siguiente.

(26) De 3 de septiembre de 2009, asuntos acumulados C-322/07/P, C-327/07P y C-338/07P. Resolución en la que no se aprecia ningún dato novedoso: se trata de un recurso de casación con origen en una sentencia delTribunal de Primera Instancia dictada en recurso de anulación contra sanciones impuestas por la Comisión en materia de Derecho de la competencia, de una duración del proceso judicial de cinco años y que, con remisión a la doctrina Baustahlgewebe, termina por desestimar al interpretar que no había habido violación del plazo razonable en atención a que los recursos (que luego se acumularon) fueron planteados por nueve empresas y tramitados en cuatro lenguas de procedimiento distintas. 


\section{A. Sentencia FIAMM y FEDON C. Comisión(27)}

A diferencia de los supuestos anteriores, en este caso el recurso de casación que conoce el Tribunal de Justicia lo es contra una sentencia desestimatoria del Tribunal de Primera Instancia, en un recurso de indemnización planteado por sendas empresas contra el Consejo de la Unión Europea y la Comisión (por un recargo aduanero exigido por los Estados Unidos de América y abonado por las recurrentes).

Pues bien, esta resolución primero confirma formalmente la vigencia de la doctrina Baustahlgewebe, pero a continuación pone de manifiesto las diferencias existentes entre una sentencia que condena al pago de una cantidad y otra que deniega una indemnización por no reunirse los requisitos para ello (como era el caso de las saga Baustahlgewebe y como es el caso de esta S. FIAMM y Fedon, respectivamente).

EITribunal de Justicia desestimará, finalmente, la pretensión compensatoria, por resultarle inencajable en una sentencia que ratifica la desestimación de una indemnización: "De ello resulta que la anulación de dicha sentencia no puede llevar a conceder una compensación equitativa en virtud de la exclusiva duración del procedimiento ante el Tribunal de Primera Instancia, por medio de la modificación de la sentencia recurrida, dado que en tal procedimiento no se pedía en ningún caso al Tribunal de Primera Instancia, como tampoco se pide en casación al Tribunal de Justicia, que condene a las partes recurrentes al pago de una cantidad de la que pudiera deducirse en su caso esa compensación equitativa» (28).

Como se ve, la distancia interpretativa con Baustahlgewebe resulta bastante clara, pero la diferencia de proceso (y, por lo tanto, de pretensión) judicial parecen pesar no poco en su fondo argumental.

\section{B. Sentencia Der Grüne Punkt C. Comisión(29)}

En este asunto se plantea la cuestión del plazo razonable en la instancia (cinco años y diez meses), en un asunto relativo a prácticas colusorias de la competencia, en el que había recaído una Decisión de la Comisión - pero consistente no en una multa, sino en una obligación de modificación de las actuaciones de determinada empresa (la diferencia es importante)-, objeto del recurso de anulación inicial.

(27) De 9 de septiembre de 2008, asuntos acumulados C-120/06P y 121/06P.

(28) S. FIAMM y Fedon c. Comisión cit., aptdo. 210. Además, de añadir, a mayor abundamiento, que en el caso no se había conculcado el principio del plazo razonable, en atención a los criterios del comportamiento de la autoridad competente y del grado de complejidad del asunto.

(29) De 16 de julio de 2009, asunto, C-385/07P. 
Pues bien, en este caso el Tribunal de Justicia, con los criterios habituales y, como novedad, con mención expresa del art. 47 de la Carta de Derechos Fundamentales de la Unión Europea - formalmente aún no en vigor, se recuerda-, a la vista de las circunstancias del caso, considera que sí se había producido lesión del plazo razonable(30). A partir de aquí conviene que nos detengamos en lo que se interpreta y decide por la Gran Sala en este nuevo rumbo.

La recurrente solicitaba de manera expresa que el Tribunal de Justicia modificase lo dicho en Baustahlgewebe, precisamente en lo relativo a que sólo procedía la anulación de la sentencia recurrida por violación del plazo razonable en la hipótesis de que la excesiva duración del proceso hubiera tenido alguna incidencia en la solución del litigio(31). La sentencia no lo estimará oportuno (32); sino incluso contraproducente(33). Y, finalmente, desestimará el recurso de casación en su integridad.

Ahora bien, constatada la lesión del plazo razonable (y así declarada en la propia sentencia), la cuestión no podía quedarse ahí sino que había que ofrecer una salida a tal circunstancia. Para ello, el Tribunal reenviará a la recurrente al recurso por indemnización sobre la base de la responsabilidad extracontractual de la Comunidad (actuales arts. 268 y 340 TFUE) (34); pero lo hará sin mayores precisiones, salvo una escueta referencia a lo dicho por el Abogado General(35). Veamos, por tanto, qué es lo que éste había sugerido.

En sus Conclusiones, el Abogado General Bot señaló que la violación del plazo razonable sólo puede dar lugar, en su caso, a una pretensión in-

(30) Y lo hace, además, de incontestable manera: «El procedimiento desarrollado ante el Tribunal de Primera Instancia incumplió las exigencias derivadas del respeto de una duración razonable del procedimiento" (aptdo. 188).

(31) Vid. supra (II.3) lo dicho a propósito del aptdo. 49 de la S. Baustahlgewebe c. Comisión cit.

(32) Y lo hará con nitidez, en estos términos: «En la medida en que no existe indicio alguno que deje traslucir que la falta de respeto de una duración razonable del procedimiento pudo tener alguna incidencia sobre el resultado del litigio, la anulación de la sentencia recurrida no repararía la violación del principio de tutela judicial efectiva [en el que el Tribunal, desde hacía dos años, venía englobando el art. 47 CDFUE] cometida por el Tribunal de Primera Instancia» (aptdo. 193).

(33) En efecto, «dada la necesidad de respetar el Derecho comunitario de la competencia, el Tribunal de Justicia no puede permitir, por la mera falta de respeto de una duración razonable del procedimiento, que la parte recurrente ponga en cuestión la existencia de una infracción, pese a haber sido desestimados por infundados todos los motivos que invocó contra las afirmaciones hechas por elTribunal de Primera Instancia a propósito de dicha infracción y del correspondiente procedimiento administrativo previo" (aptdo. 193)

Más claramente aún lo había dicho el Abogado General Bot: «la sanción de la violación del plazo razonable del procedimiento no puede, en ningún caso, conducir a que una empresa pueda continuar o reanudar un comportamiento que ha sido declarado contrario a las normas comunitarias" (aptdo. 306 de sus Conclusiones presentadas el 31 de marzo de 2009).

(34) Vid. S. Der Grüne Punkt c. Comisión cit., aptdo. 195.

(35) En los aptdos. 307 y ss. de sus Conclusiones cit. 
demnizatoria del perjuicio soportado; perjuicio que, en el caso de la empresa infractora, en ningún momento le supuso un daño económico (aptdo. 308). Pero también es cierto que el derecho a que su causa sea vista en un plazo razonable tiene tanta importancia que, el mero hecho de privar a una persona física o jurídica de esta garantía, constituye -a su juicio - un perjuicio autónomo por sí solo (aptdo. 313). Entonces, ¿cómo y ante quién habrá de materializarse su reparación? Aquí viene la novedosa aportación del Abogado General.

Lo primero que señala es que no existen en el ordenamiento comunitario disposiciones específicas sobre las acciones de indemnización causadas por el funcionamiento de la justicia comunitaria y que la sugerencia del Abogado General en Baustahlgewebe -que fuese el propio Tribunal de Justicia el que la asumiese (lo que, como sabemos, éste no admitiría) (36) - , tras Niza, no podría sostenerse porque iría en contra de las competencias atribuidas por el Derecho originario al Tribunal de Primera Instancia, entre las que está, expresamente, el conocimiento del recurso de indemnización contra las instituciones europeas o sus agentes (ahora, ex art. 256.1 TFUE). Se plantea, entonces, si el conocimiento de un recurso de indemnización de los de este tipo por el propioTribunal de Primera Instancia podría ir en contra del principio de imparcialidad; y, tras repasar la jurisprudencia del Tribunal Europeo de Derechos Humanos sobre la imparcialidad objetiva, llega a la conclusión de que "le parece razonable sostener su competencia [la delTribunal de Primera Instancia, ahora Tribunal General se entiende], bajo la condición expresa de que la composición que conoce del recurso sea distinta de la que adoptó el acto o de la que resultó el perjuicio alegado" (37). Esto es, así, lo dicho por el Abogado General, al que se remite discretamente la sentencia.

Como se ve, en este importante pronunciamiento de la Gran Sala, ya se asienta una doble interpretación clave, en el caso de que el (entonces) Tribunal de Primera Instancia no respete el plazo razonable en sus procesos: 1. $^{a}$ ) se cierra definitivamente el paso a la pretensión de obtener una reparación en el proceso casacional ante el Tribunal de Justicia (esto es, hay una rectificación en toda regla de la solución "endoprocesal» arbitrada en Baustahlgewebe); . $^{\text {a) }}$ la violación del plazo razonable por parte del Tribunal de Primera Instancia "puede dar lugar a una pretensión de indemnización" al amparo de un recurso de indemnización(38). Haría falta alguna precisión más, con respecto a este (nuevo) recurso de indemnización a emprender por la parte perjudicada, pero la sentencia no la aporta

(36) Vid. supra aptdo. II.2.

(37) Aptdo. 337 de las Conclusiones cit. (la cursiva está añadida).

(38) S. Der Grüne Punkt c. Comisión cit., aptdo. 195. 
- aunque sí el Abogado General, como hemos visto- y tendremos que esperar más de cuatro años hasta que el Tribunal da Justicia explicite su nueva interpretación (que, se adelanta ya, lo hará en el sentido propuesto por el Abogado General).

\section{Sentencia Gogos C. Comisión(39)}

Esta sentencia tiene un interés limitado a los efectos que aquí interesan, pero quizá no esté de más mencionarla, por lo que al asunto aportó la Abogada General. El ámbito material del recurso que origina esta sentencia es muy distinto de todo lo ya visto, pues se dicta en un recurso de casación contra otra del Tribunal de Primera Instancia que había desestimado a un funcionario la anulación de una Decisión "de clasificación» de la Comisión que afectaba a su estatus funcionarial. Se reitera ante el Tribunal de Justicia la tacha de violación del plazo razonable (cuatro años y ocho meses) y, por esta razón, se solicita una indemnización de cincuenta mil euros. La sentencia entiende que el retraso no ha tenido incidencia alguna en la solución de litigio (40) y desestima el recurso, sin ulteriores indicaciones al respecto.

La Abogada General Kokott, en cambio, admitía la posibilidad de que hubieran existido unas dilaciones indebidas (que el Tribunal de Justicia, se insiste, no declara), pero que ello debería ventilarse $-y$ esto es lo que aquí puede tener más interés - por la vía del específico recurso de indemnización (41).

\section{La posterior y definitiva interpretación que remite a la vía del recurso de indemnización}

Como acabamos de ver, la solución "endoprocesal» de Baustahlgewebe -que ya en su momento fue discutida por el Abogado General, como sabemos - empezó a rectificarse una decena de años después. Pero no será hasta 2013 cuando podamos decir, con visos de definitivi-

(39) De 20 de mayo de 2010, asunto C-583/08P.

(40) En razonamiento que nos resulta ya conocido y con referencia a Baustahlgewebe c. Comisión, FIAMM y Fedon c. Comisión y Der Grüne Punkt c. Comisión (vid. S. Gogos c. Comisión cit., aptdos. 56 y 57).

(41) Concluía así su examen del asunto: "Sin perjuicio de un examen más minucioso en el marco de un eventual procedimiento de indemnización, dicha duración del procedimiento no parece estar justificada ni por una especial complejidad de la materia o de las cuestiones de hecho y de Derecho planteadas, ni por la conducta de las partes" (aptdo. 88 de las Conclusiones presentadas el 4 de marzo de 2010, la cursiva está añadida). 
dad, que la compensación por los daños que hubiera podido sufrir un justiciable ante el Tribunal General deberá pretenderse por la vía, autónoma, del recurso de indemnización.

\section{El punto de inflexión: las sentencias Gascogne Sack Deutschland c. Comisión y otras}

Tres pronunciamientos de la Gran Sala de la misma fecha, que resuelven de igual manera y con idéntica ratio decidendi otros tantos recursos de casación (42), constituyen la consolidación - plenamente consciente (43) - del cambio interpretativo delTribunal de Justicia.

En efecto, en un asunto análogo al resuelto en Bausthalgewebe(44), el Tribunal de Justicia desarrollará su (nuevo) razonamiento de la siguiente manera (45). En primer lugar, reconoce que el recurso de casación es un proceso apto para controlar las irregularidades que, lesionando los intereses del recurrente, hubiera podido cometer el Tribunal General; y, entre ellos, sin duda alguna, se encuentra la violación del plazo razonable garantizado por el art. 47 CDFUE.

A continuación, recuerda las exigencias derivadas del Convenio Europeo de Derecho Humanos (46) en lo referente a que la inobservancia del plazo razonable debe abrir a la parte afectada la posibilidad de interpo-

(42) Son tres sentencias de 26 de noviembre de 2013: la Sentencia Gascogne Sack Deutschland c. Comisión, C-40/12P, la Sentencia Kendrion c. Comisión, C-50/12P y la Sentencia Groupe Gascogne c. Comisión, C-58/12P. También las Conclusiones de los tres asuntos fueron elaboradas por la misma Abogada General (Sharpston) y presentadas en la misma fecha (el 30 de mayo de 2013), aunque formalmente individualizadas.

(43) Buena prueba de lo que se afirma es lo recogido en las Conclusiones cit. en el as. Groupe Gascogene (aptdo. 119), donde se señala que, durante la tramitación del proceso, "[e]ITribunal de Justicia instó a los veintisiete Estados miembros, al Parlamento Europeo y al Consejo a expresar por escrito su opinión con respecto a los criterios adoptados respectivamente en las sentencias Baustahlgewebe y Der Grüne Punkt. Siete Estados miembros manifestaron su preferencia por el criterio adoptado en la primera sentencia, tres por el de la última y seis Estados miembros no expresaron ninguna preferencia. El Consejo respaldó el criterio de la sentencia Baustahlgewebe, aunque reconoció que las dos vías de recurso coexisten y que ninguna es perfecta. El Parlamento Europeo se inclinó por el criterio de la sentencia Der Grüne Punkt».

(44) Como la propia S. Gascogne Sack Deutschland c. Comisión cit., aptdo. 88, reconoce explícitamente.

(45) S. Gascogne Sack Deutschland c. Comisión cit., aptdos. 74 a 103; en la S. Kendrion c. Comisión cit., lo hará en los aptdos. 77 a 108 y en la S. Groupe Gascogne c. Comisión cit., en los aptdos. 66 a 97. En los tres casos muchos de los apartados resultan idénticamente redactados.

(46) Tal y como lo interpretó el Tribunal de Estrasburgo en su fundamental STEDH de 26 de octubre de 2000, caso Kudla c. Polonia, aptdos. 156 y 157. Vid., a este propósito, el comentario de SAIZ ARNAIZ, A., "El derecho a un proceso "dentro de un plazo razonable" y la "necesaria" existencia de remedios nacionales ante su vulneración. Un trascendental cambio en la jurisprudencia del TEDH (comentario a la Sentencia Kudla c. Polonia, de 26 de octubre de 2000)", en Repertorio Aranzadi del Tribunal Constitucional núm. 3, 2000, págs. 1821 y ss. 
ner un recurso efectivo capaz de ofrecer una reparación adecuada (47). Adelantando un poco el análisis, conviene precisar desde ahora que la duración del proceso le parecerá al Tribunal de Justicia injustificable (48), reconociendo expresamente la conculcación de dicho derecho fundamental(49).

La sentencia reitera su ya mencionada doctrina consistente en que, si la excesiva duración del pleito no ha influido en la solución del litigio - como era el caso, podemos precisar-, no procede anular la sentencia recurrida(50). Pero sucedía que la recurrente había pedido la reducción de la misma por los perjuicios que le había ocasionado el retraso en la tramitación de su recurso de anulación, con invocación expresa de la solución Bausthalgewebe. Y aquí es donde el Tribunal de Justicia, con apoyo en la S. Der Grüne Pûnkt c. Comisión -que, recuérdese, no se refería a una condena al pago de cantidad alguna-, se separará de lo dicho en Baustahlgewebe(51) y afirmará, de una manera clara y rotunda, coincidente con lo propuesto por la Abogada General Sharpstone(52), que la

(47) El "remedio efectivo» al que se refiere el conocido art. $13 \mathrm{CEDH}$ (aunque la sentencia no lo identifica).

(48) S. Gascogne Sack Deutschland c. Comisión cit., aptdos. 97 y 102.

(49) Extremo, éste último, que posteriormente producirá alguna reticencia en el Abogado General Wahl, para quien el Tribunal de Justicia no debe hacer un pronunciamiento explícito de este tipo, por razones de defensa; con lo que, a su juicio, "la jurisprudencia del Tribunal de Justicia invocada por las recurrentes, que no aconsejo al Tribunal de Justicia aplicar en el futuro, únicamente tiene sentido si se limita a circunstancias realmente excepcionales en las que la falta de carácter razonable del procedimiento es tan manifiesta e incuestionable que, objetivamente, no puede justificarse en ningún caso. Salvo en esos supuestos excepcionales, únicamente puede resolverse sobre una alegación relativa a la vulneración del derecho a ser juzgado en un plazo razonable tras la celebración de un procedimiento inter partes en el que se permita a la demandada exponer sus argumentos de defensa y, en su caso, aportar pruebas en su apoyo. Como ya ha declarado de forma reiterada el Tribunal de Justicia, "el carácter razonable de [un] plazo debe apreciarse en función de las circunstancias propias de cada asunto y, en particular, de la transcendencia del litigio para el interesado, de la complejidad del asunto, del comportamiento del demandante y del de las autoridades competentes». En mi opinión, en la mayor parte de los asuntos esa apreciación de todas las circunstancias no constituye en modo alguno un ejercicio simple y directo" (Conclusiones presentadas en el as. Feralpi c. Comisión, el 8 de diciembre de 2016, asuntos acumulados C-85, 86, 87, 88 y 89/15P, aptdo. 75).

(50) Interpretación que será asumida por el Tribunal General. Vid. su Sentencia HIT Groep c. Comisión, de 15 de julio de 2015, T-436/10, aptdos. 285-286.

(51) De hecho, en su Informe Anual 2013, refiriéndose a este grupo de las tres sentencias ahora comentadas, el propio Tribunal de Justicia reconocerá que «se apartó de la solución recogida en su sentencia de 17 de diciembre de 1998, Baustahlgewebe/Comisión, al desestimar la solicitud, a estos efectos [se refería al remedio adecuado para reparar las consecuencias económicas resultantes de la duración excesiva del procedimiento], en el marco de un recurso de casación, de reducción del importe de las multas impuestas» (pág. 5).

(52) En las Conclusiones cit., en el as. Groupe Gasgone c. Comisión, alguno de cuyos apartados merece recogerse aquí:

"127. He aquí la razón por la que no estoy de acuerdo con el criterio adoptado en la sentencia Baustahlgewebe. Multar a una empresa por vulnerar las normas sobre competen- 
indemnización procedente por tales perjuicios debería articularse, precisamente, por la vía del recurso de indemnización (ex arts. 268 y 340 TFUE), constituyendo este tipo de proceso el "remedio efectivo" establecido por el ordenamiento de la Unión Europea para el caso de la violación del plazo razonable.

Ahora bien, esta solución reenvía directamente al Tribunal General, que es el que tiene atribuida la competencia para conocer de este tipo de recursos indemnizatorios contra la Unión Europea (según viene establecido en el art. 256.1 TFUE), pero que es a quien se le imputa la lesión, cabalmente. Para obviar esta dificultad $-y$ adoptando la solución que, inicialmente, había propuesto el Abogado General Bot en el asunto Der Grüne Punkt c. Comisión y que, ahora, secunda también la Abogada Ge-

cia no puede equipararse a la condena a una pena de privación de libertad de una persona física, supuesto en que el retraso en el juicio puede de hecho compensarse de forma efectiva (si la persona física es declarada culpable y condenada a una pena de prisión), mediante la reducción del tiempo de cumplimiento de la pena de prisión. Por otra parte, si la empresa ha sufrido un perjuicio a causa del retraso, dicho perjuicio puede desglosarse en pérdidas financieras concretas relacionadas causalmente con el retraso excesivo sufrido en la resolución del recurso. Se pueden aportar elementos de prueba y, una vez probado el daño, podrá concederse la indemnización apropiada. En el ordenamiento jurídico de la Unión corresponde al Tribunal General y no al Tribunal de Justicia examinar los hechos en profundidad y evaluar los elementos de prueba. Opino que este es otro argumento a favor de la conclusión de que sería preferible la interposición de un recurso de indemnización separado ante el Tribunal General en vez de intentar ofrecer un recurso efectivo mediante la reducción de las multas en el marco del recurso de casación.

[...].

131. No me resulta claro de qué modo el artículo 261 TFUE (invocado por el Tribunal General) constituye una base satisfactoria para la reducción de una multa, cuando no existen motivos sustantivos para desvirtuar la apreciación de la Comisión de que la multa era apropiada con respecto a la infracción. Es cierto que el artículo 31 del Reglamento $n .^{\circ} 1 / 2003$ y el artículo 261 TFUE otorgan al Tribunal General (y, en vía de recurso, al Tribunal de Justicia) "competencia jurisdiccional plena"; pero esta competencia jurisdiccional plena está estrechamente ligada al carácter apropiado (o no) de la sanción impuesta con respecto a la infracción cometida. El retraso de un procedimiento - ya sea causado por la Comisión en la vía administrativa o por el Tribunal General en la vía contenciosa - no guarda relación alguna con el comportamiento de la empresa o la gravedad de la infracción.

132. Soy consciente de que el rigor de este criterio no coincide con el enfoque adoptado por el Tribunal General al examinar alegaciones de retraso indebido. Tampoco corresponde al criterio adoptado por el Tribunal de Justicia en la sentencia Baustahlgewebe. No obstante, creo que el Tribunal de Justicia se encuentra ahora en una situación en la que puede y debe pronunciarse sobre cuál es la mejor de las dos vías de recurso actualmente disponibles. Comprendo que, en el marco de un recurso, es tentador, en aras de la economía procesal, inclinarse por la reducción de la multa (en un porcentaje indeterminado, calculado sobre una base desconocida). No obstante, no me convence el fundamento lógico de tal criterio (en términos de la relación entre la multa y el comportamiento, la competencia jurisdiccional y la transparencia), que además, en el peor de los casos, puede convertirse en un criterio casi totalmente arbitrario. (Debo añadir que la situación sería muy diferente si el legislador decidiese introducir normas específicas para regular el efecto que debe tener en el importe de las multas, la existencia de un retraso indebido en la vía administrativa o en la contenciosa, en asuntos en materia de competencia; pero, según creo, hasta ahora no se ha explorado esta posibilidad)». 
neral Sharpstone-, el Tribunal de Justicia formula la salvedad expresa de que, cuando el Tribunal General resuelva este recurso de indemnización, lo haga "fallando en una formación diferente de la que conoció del litigio que dio lugar al procedimiento cuya duración se critica» (53). Aunque bien es verdad que lo hace sin mayores consideraciones y sin mención alguna al principio de imparcialidad (que es el que, de manera indudable, está en el origen de esta cautela) (54).

Pero el Tribunal de Justicia no se limita a esta remisión condicionada, sino que aprecia en el caso (y así lo declara formalmente) la existencia de una dilación indebida en el proceso judicial a quo, siguiendo en esto la solución sugerida por la Abogada General(55). En efecto, aunque el

(53) S. Gascogne Sack Deutschland c. Comisión cit., aptdo. 96 (la cursiva está añadida).

(54) Mención que sí hacía el Abogado General Bot en el as. Der Grüne Punkt (como se ha dejado dicho) y que ahora hace la Abogada General Sharpstone en el as. Groupe Gasgone, de la siguiente manera:

«145. Opino que el verdadero problema es si el Tribunal General sería percibido como órgano imparcial al resolver un recurso de indemnización basado en la alegación de que el propio Tribunal General es responsable de la vulneración de los derechos fundamentales del recurrente.

146. En mi opinión, existen elementos suficientes para inclinarnos por considerar que el Tribunal General puede ser percibido de forma razonable como suficientemente imparcial.

147. En primer lugar, el pago de la indemnización concedida no provendría del propio Tribunal General. Saldría del presupuesto de la Unión Europea, con lo cual el Tribunal General no tendría ningún interés directo en las consecuencias financieras del procedimiento. En segundo lugar, para poder cumplir con el requisito subjetivo de la imparcialidad personal, el Tribunal General deberá asegurarse de que el recurso de indemnización sea oído por una sala diferente de la que conoció del litigio en el que se produjo el retraso excesivo. En tercer lugar, en la medida en que la alegación de vulneración del artículo 47 de la Carta probablemente se plantee en vía de recurso de casación y no ante el Tribunal General, será el Tribunal de Justicia quien apreciará la existencia de un retraso excesivo. La labor del Tribunal General quedaría restringida a la prueba del perjuicio y la evaluación de la cuantía. En cuarto lugar, aunque la situación que motiva el procedimiento por la vulneración del artículo 47 de la Carta es competencia del Tribunal General, corresponderá a la Comisión, en su función de promover el interés general de la Unión de conformidad con el artículo 17 TUE, apartado 1, defender a la Unión en el procedimiento ante dicho Tribunal [adviértase que este extremo quedará luego desmentido por las sentencias de 2017 que veremos en el apartado siguiente]. En quinto lugar, cualquier resolución del Tribunal General obviamente quedaría sujeta al control de las cuestiones de Derecho por el Tribunal de Justicia.

148. Por consiguiente, llego a la conclusión de que, en cuanto a la alegación del recurrente de haber sufrido un perjuicio derivado del hecho de que el Tribunal General no resolvió su recurso en un plazo razonable, la interposición de un recurso de indemnización ante el Tribunal General constituye una solución más adecuada y eficaz a los efectos del artículo 47 de la Carta, interpretado a la luz de los artículos $6 \mathrm{CEDH}$, apartado 1, y $13 \mathrm{CEDH}$, que una reducción del importe de la multa. En la medida en que sea necesario reconocer expresamente la infracción del Tribunal General al margen de un posible recurso de indemnización, opino que una declaración del Tribunal de Justicia a estos efectos constituye una reparación adecuada.»

(55) En las mismas Conclusiones cit. (la cursiva está añadida):

"149. Procede examinar una última cuestión: ¿cuál sería “el hecho que [...] motivó" la responsabilidad extracontractual de la Unión a los efectos del artículo 46 del Estatuto 
Tribunal de Justicia desestima la petición de rebaja de la cuantía de la multa, declara la existencia de una vulneración del art. 47 CDFUE y afirma literalmente que tal actuación «constituye una violación suficientemente caracterizada de una norma jurídica que tiene por objeto conferir derechos a los particulares» (56). En buena lógica, esto debería significar que, en el eventual recurso posterior ante el Tribunal General, no podría ignorarse la existencia de este requisito básico para la responsabilidad extracontractual que se acaba de mencionar y sólo cabría analizar los demás elementos necesarios para establecer la indemnización. Ya veremos un poco más adelante, sin embargo, que las cosas no han resultado exactamente así.

Además de esta declaración, también tiene importancia otra doble precisión, de tipo material, que le hace el Tribunal de Justicia al Tribunal General para estos casos, referida a la exigencia de que respete ciertos criterios de fondo en su enjuiciamiento (57). Así, en primer lugar, para la apreciación de la violación del plazo razonable, le señala que deberá tener en cuenta los criterios "clásicos" que, como es sabido, tienen su principal fuente de inspiración en la jurisprudencia delTribunal de Estrasburgo (al interpretar y aplicar el art. 6.1 CEDH) (58). Y, en segundo lugar, le indica los típicos elementos para dilucidar la existencia de una responsabilidad extracontractual: la realidad del daño y la relación de causalidad entre éste y la duración excesiva del procedimiento; pero con un par de precisiones más a este respecto, como son la exigencia de tener en consideración los principios generales aplicables en los ordenamientos de los Estados miembros para casos similares (hay que entender que por lo establecido en el párrafo segundo del art. 340 TFUE), por un lado, $y$, además de la existencia del daño material, la de un posible daño inmaterial, por otro.

\begin{abstract}
del Tribunal de Justicia? En mi opinión, ese hecho es necesariamente la conclusión del Tribunal de Justicia de que se ha producido un retraso indebido en el procedimiento ante el Tribunal General. De ello se deduce, que el plazo de prescripción de cinco años previsto para la interposición de dicho recurso de indemnización empezaría a computarse a partir de la fecha en que el Tribunal de Justicia dicte sentencia en el presente recurso.

150. Por consiguiente, propongo que el Tribunal de Justicia declare que se ha producido un retraso excesivo en la resolución del recurso interpuesto por Groupe Gascogne ante el Tribunal General; y sugiero asimismo que el Tribunal de Justicia señale claramente que Groupe Gascogne puede interponer un recurso separado de indemnización de daños y perjuicios, si así lo desea».
\end{abstract}

(56) S. Gascogne Sack Deutschland c. Comisión cit., aptdo. 102.

(57) S. Gascogne Sack Deutschland c. Comisión cit., aptdos. 91 a 95

(58) Como expresamente le había sugerido la Abogada General Sharpstone en sus Conclusiones cit., en el as. Groupe Gascogne c. Comisión, aptdo. 72 (con cita, además, de jurisprudencia del propioTribunal de Justicia al respecto). 
Estos matices recogidos en el párrafo anterior, frente a lo que a primera vista pudiera parecer, no son ni impertinentes, ni gratuitos ni redundantes, puesto que le fijan o establecen un marco al Tribunal General - a la hora de resolver un asunto que le afecta tan directamente- que puede constituir una garantía efectiva frente al peligro de "autodefensa" o excesiva comprensión hacia sus propias actuaciones jurisdiccionales, en un supuesto en el que enjuicia, precisamente, una actuación previa suya tachada de incorrecta y lesiva. Dicho de otra manera, cuando en el marco de un recurso por indemnización el Tribunal General -en una formación jurisdiccional distinta, se insiste - conozca de un asunto en el que se dilucide si ha habido una previa actuación suya constitutiva de una lesión del derecho al enjuiciamiento en plazo razonable, no puede establecer unos criterios más restrictivos o rigurosos a la hora de analizar una posible responsabilidad patrimonial de la Unión que los que ya le ha señalado el Tribunal de Justicia.

No parece muy aventurado deducir de lo anterior un intento por parte del Tribunal de Justicia de evitar la tacha de proponer una vía que, al quedar en manos de quien había originado la lesión, pudiera tildarse de inefectiva por articularse de una manera que haga prácticamente imposible o excesivamente difícil obtener la indemnización (por utilizar una fórmula muy conocida en el Tribunal de Justicia, cuando de aplicar el principio de efectividad se trata). Veremos sin embargo, un poco más adelante, cómo el Tribunal General ha soslayado con solvencia estos riesgos y, además, frente a una muy cerrada oposición procesal.

Analizaremos en seguida la continuación de esta historia jurisprudencial, puesto que algunas de las empresas afectadas en estas sentencias decidirán transitar la vía del recurso de indemnización que les señalaba el Tribunal de Justicia en estas resoluciones que acabamos de comentar.

\section{Otros pronunciamientos que ratifican esta interpretación}

Las sentencias mencionadas en el apartado anterior han tenido continuidad en otras posteriores, también dictadas por el Tribunal de Justicia en diversos recursos de casación(59). En todas ellas se ratifica expresa-

(59) Como son la Sentencia Deltafina c. Comisión, de 12 de junio de 2014, C-578/11P, aptdos. 80 a 93; la Sentencia FLS Plast A/S c. Comisión, de 19 de junio de 2014, C-243/12P, aptdos. 130 a 144; la Sentencia Telefónica c. Comisión, de 10 de julio de 2014, C-295/12P, aptdos. 62 a 69; la Sentencia ICF c. Comisión, de 9 de octubre de 2014, C-467/13P, aptdos. 55 a 66; la Sentencia Guardian Industries Corp. c. Comisión de 12 de noviembre de 2014, C-580/12P, aptdos.15 a 21; la Sentencia Galp Energía España c. Comisión, de 21 de enero de 2016, C-603/13P, aptdos. 55 a 59; la Sentencia CEPSA c. Comisión, de 9 de junio de 2016, C-608/13P, aptdos. 64 a 67; la Sentencia REPSOL c. Comisión, de 9 de junio de 2016, C-617/13P, aptdos. 98 a 103; la Sentencia Trafilerie Meridional c. Comisión, de 14 de septiembre de 2016, C-519/15P, aptdos. 65 a 68; y la Sentencia Aloys F. Dornbracht c. Comisión, de 26 de enero de 2017, C-604/13P, aptdos. 97 a 99. 
mente lo recién visto (60), con fundamentación jurídica idéntica (61); razón por la que no procede insistir más en ello ahora.

\section{Aplicación efectiva del recurso de indemnización en el caso de dilaciones indebidas}

\section{Primeras sentencias}

Consecuencia lógica de la nueva interpretación del Tribunal de Justicia sobre la vía adecuada para exigir una compensación había de ser que las personas afectadas por el incumplimiento del plazo razonable ejerciesen la correspondiente acción indemnizatoria, ex art. 268 TFUE, ante el Tribunal General (62). Así lo hicieron las tres empresas que habían visto desestimada su pretensión en las sentencias del Tribunal de Justicia de 26 de noviembre de 2013, recién comentadas, dando lugar a dos destacadas sentencias del Tribunal General (63).

(60) En efecto, la cuestión resulta definitivamente zanjada en favor de la más reciente interpretación aquí analizada ya con suficiente detenimiento. Incluso aunque todavía se haya manifestado alguna reticencia, como es la del Abogado General Wathelet, en las Conclusiones presentadas el 29 de abril de 2014, en el as. Guardian Industries Corp. c. Comisión, en las que manifiesta explícitamente su criterio favorable a la interpretación Baustahlgewebe: «En mi opinión, el mecanismo de reparación apropiado para una violación del principio del plazo razonable por el Tribunal General en un asunto como el de autos sería - por motivos de economía procesal pero también para garantizar una tutela judicial efectiva e inmediata - una reducción de la multa, en vez de hacer que las partes interpongan una reclamación por daños y perjuicios ante el Tribunal General, del cual se ha establecido, por definición, que incumplió dicho principio al no garantizar la emisión de una resolución dentro de un plazo razonable», (aptdo. 110). Pero donde reconoce inmediatamente que, tras las sentencias Gascogne Sack Deutschland et alia c. Comisión, el Tribunal de Justicia «abandonó claramente» tal interpretación y «por tanto me veo obligado a razonar sobre dicha base en el presente asunto» (aptdo. 119).

(61) Aunque es verdad que en tres de los pronunciamientos citados supra, en la nota 59, el Tribunal de Justicia no declara la existencia de la violación del art. 47 CDFU, por considerar que no tiene elementos de juicio suficientes como para adverar la conculcación del plazo razonable, defiriendo tal constatación al eventual recurso de indemnización que se plantee posteriormente ante el Tribunal General (vid. la S. Telefónica c. Comisión cit., aptdo. 68; la S. Trafilerie Meridional c. Comisión cit. aptdo. 68; y la S. Aloys F. Dornbracht c. Comisión cit., aptdo. 100).

(62) Y, aunque no hay una referencia expresa a esta cuestión en ninguna de las sentencias dictadas hasta el momento, todas ellas lo han sido por la Sala Tercera ampliada de este Tribunal General; lo que ha de entenderse como una formación distinta de la que conoció de los recursos de anulación que están en el origen de las reclamaciones por los daños producidos por indebidas dilaciones.

(63) Se trata de la Sentencia Gascogne Sack Deutschland y Gascogne c. Unión Europea, de 10 de enero de 2017, T-577/14, en recurso conjunto planteado por las dos empresas recurrentes en los as. 40/12P y 58/12P; y de la Sentencia Kendrion c. Unión Europea, de 1 de febrero de 2017, T-479/14, en recurso planteado por la empresa recurrente en el as. 50/12P (los tres asuntos citados supra, en la nota 42). Ambas resoluciones son muy similares y vienen a plantear las mismas cuestiones, razón por la que aquí se manejarán de manera conjunta. Un comentario monográfico a la primera de ellas en OVÁDEK, M., "At Last! Reaching the remedy for delay after a long ride through the EU judicial system", en Maastricht Journal of European and Comparative Law, núm. 3, 2017, págs. 438 y ss. 
Frente a lo que pudiera parecer - dado que el Tribunal de Justicia ya había declarado expresamente la conculcación del plazo jurisdiccional razonable en los correspondientes recursos de anulación ante el Tribunal General y, por lo tanto, aparentemente sólo habrían de discutirse las cuestiones relacionadas con el daño (esto es, la relación de causalidad y el cálculo de la indemnización, en su caso)-, el ejercicio efectivo del recurso de indemnización transcurrió por un camino procesal bastante más tortuoso. Merece mencionarse, siquiera someramente, los obstáculos encontrados porque son una buena muestra de las dificultades de articulación que suelen presentar las exigencias de responsabilidad por actuaciones de las más altas instancias jurisdiccionales.

En efecto, el Tribunal de Justicia de la Unión Europea - esto es, la institución de la Unión Europea a que se refieren, fundamentalmente, los arts. 13 y 19 TUE (64) - planteó al Tribunal General una doble excepción previa de inadmisibilidad del recurso, fundada (por lo que aquí más interesa) en que las demandantes no habían identificado la institución encargada de representar a la Unión (que es quien tiene la personalidad jurídica, a efectos de la imputación del daño). El Tribunal de Justicia consideraba, en definitiva, mal planteado el recurso porque no se establecía que a la Unión le representaría la Comisión Europea, sino el propio Tribunal de Luxemburgo (65). El Tribunal General, sin embargo, rechazará la inadmisibilidad sin reticencia alguna (66).

Tras esta desestimación, la Comisión solicitó intervenir en el recurso como coadyuvante en apoyo de las pretensiones delTribunal de Justicia de la Unión Europea. Cosa que sí fue aceptada por el Tribunal General (67).

Obviando algún otro incidente procesal y planteado definitivamente el proceso ante el Tribunal General como un recurso de indemnización de las demandantes contra la Unión - representada por el Tribunal de Justicia de la Unión Europea, apoyado por la Comisión-, podemos pasar a analizar lo

(64) Institución única, por tanto, aunque articulada en dos órganos o instancias jurisdiccionales diferenciadas, que son el Tribunal de Justicia y el Tribunal General (desde la desaparición del Tribunal de la Función Pública, el 1 de septiembre de 2016), como es sabido.

(65) Recuérdese a este propósito lo sugerido por la Abogada General Sharpstone en el aptdo. 147 de sus Conclusiones en el as. 58/12P, recogido supra, en la nota 54.

(66) Las detalladas razones - cuya referencia pormenorizada nos detendría en exceso- del Tribunal General se pueden encontrar en su Auto de 2 de febrero de 2015, T-577/14, y en su Auto de 6 de enero de 2015, T-479/14, respectivamente. Ambos autos desestimatorios de las excepciones de inadmisibilidad serían recurridos en casación por el Tribunal de Justicia de la Unión Europea, aunque de ambos desistiría poco después, ordenándose su archivo por el Tribunal de Justicia en el Auto Tribunal de Justicia de la Unión Europea c. Gacogne Sack Deutschland y Gascogne, de 18 de diciembre de 2015, C-125/15P y en el Auto Tribunal de Justicia de la Unión Europea c. Kendrion, de 18 de diciembre de 2015, C-71/15P.

(67) Si bien con efectos sólo a partir de la fase oral del procedimiento (vid. su autos de 15 de marzo de 2016, T-577/14 y T-479/14) 
resuelto por las dos primeras sentencias de este tipo. Y lo primero que tienen que sortear son dos nuevas causas de inadmisibilidad de las demandas planteadas por el Tribunal de Justicia de la Unión Europea (la falta de claridad de las demandas y la prescripción de la acción), que también acaba rechazando elTribunal General (68).

En cuanto al fondo de la pretensión indemnizatoria, lo primero que se aborda es la existencia misma de la conculcación del plazo razonable, resultando llamativo que, habiendo sido ya objeto tal cuestión de una declaración expresa e indubitada por la Gran Sala del Tribunal de Justicia(69), ahora el Tribunal de Justicia de la Unión Europea alegue lo contrario. El Tribunal General, sin embargo, analizando detenidamente todas las fases de los procesos tachados de indebidamente dilatados, por un lado, ratificará la violación del plazo razonable y, por otro, considerará que tal conculcación constituye una "violación suficientemente caracterizada», a efectos de la obtención de la indemnización (extremo al que haremos referencia en el apartado siguiente). Así las sentencias dirán, expresamente $-\mathrm{y}$ conviene reseñarlo por lo que más adelante se dirá al respecto-, que se «vulneró el artículo 47, párrafo segundo, de la Carta de los Derechos Fundamentales, al haber rebasado su duración en 20 meses el plazo razonable de enjuiciamiento, lo cual constituye una infracción suficientemente caracterizada de una norma de Derecho de la Unión dirigida a conferir derechos a los particulares» (70).

Sentado lo anterior, el Tribunal General analizará la relación de causalidad, admitiéndola para el caso de los gastos de garantía bancaria durante el periodo de exceso en la tramitación del procedimiento judicial (71).

\footnotetext{
(68) Ambas, como se ha dicho en el texto, resultan desestimadas por el Tribunal General; pero interesa aquí más el argumento utilizado contra la segunda de ellas (que sólo se plantea en el as. Gascogne), esto es, la relativa a la prescripción: «en el caso concreto de un recurso de indemnización dirigido a obtener la reparación de un perjuicio supuestamente sufrido debido a una posible inobservancia del plazo de enjuiciamiento razonable, el día a partir del cual empieza a correr el plazo de prescripción de cinco años previsto en el artículo 46 del Estatuto del Tribunal de Justicia de la Unión Europea debe establecerse, cuando el plazo de enjuiciamiento de que se trata ha concluido con una resolución, en la fecha en que se adoptó tal resolución. En efecto, dicha fecha constituye una fecha cierta, fijada con arreglo a criterios objetivos. Garantiza la observancia del principio de seguridad jurídica y permite la protección de los derechos de las demandantes" (S. Gascogne Sack Deutschland y Gascogne c. Unión Europea cit., aptdo. 47). La misma objeción y la misma respuesta nos aparecerá en las posteriores sentencias citadas infra, en la nota 75 y en la nota 78 , respectivamente.
}

(69) Recuérdese lo dicho por la S. Gascogne Sack Deutschland c. Comisión cit., la S. Groupe Gascogne c. Comisión cit. y la S. Kendrion c. Comisión cit. (vid. supra, en el apartado IV.1, el texto correspondiente a la nota 49).

(70) S. Gascogne Sack Deutschland y Gascogne c. Unión Europea cit., aptdo. 78 y de idéntica manera en la S. Kendrion c. Unión Europea cit., aptdo. 63.

(71) S. Gascogne Sack Deutschland y Gascogne c. Unión Europea cit., aptdo. 121 y de idéntica manera en la S. Kendrion c. Unión Europea cit., aptdo. 99. 
Y, en cuanto a la indemnización a otorgar, considerará probada la existencia de un perjuicio material por tales gastos(72), así como la de un daño moral por la misma causa (73).

\section{Sentencias posteriores}

Además de un recurso de indemnización que el Tribunal General desestima por no considerar cumplido el requisito básico de la vulneración del art. 47 CDFUE (74), tenemos otras dos sentencias estimatorias que van en la misma línea que las iniciales recién analizadas y que procede mencionar.

La primera se dicta en febrero de $2017(75)$ y, a diferencia de las dos vistas en el apartado anterior, la recurrente no había obtenido previamente del Tribunal de Justicia un pronunciamiento expreso sobre la existencia del incumplimiento del plazo razonable en los correspondientes recursos de anulación ante el Tribunal General a los que, ahora, se tacha de indebidamente dilatados. Tras la superación de las consabidas excepciones de inadmisibilidad y también con la oposición frontal del Tribunal de Justicia de la Unión Europea, en este caso el Tribunal General considera asimismo injustificada su duración(76); en consecuencia, declara vulnerado el art. 47 CDFUE - lo que le resulta constitutivo de una violación suficientemente caracterizada del Derecho de la Unión (aptdo. 83), se insiste- y otorga la correspondiente indemnización (77).

La segunda sentencia es de junio de 2017 (78) y, como en los dos primeros casos comentados, el recurso lo plantea la empresa que había

(72) Que la S. Gascogne Sack Deutschland y Gascogne c. Unión Europea cit., aptdo. 143, fija en $47.064,33$ euros y la S. Kendrion c. Unión Europea cit., aptdo. 108, fija en 588.769,18 euros.

(73) Que se establece ex aequo et bono, como suele ser usual en este tipo de daños, con una cantidad global: 5.000 euros para las empresas recurrentes en la S. Gascogne Sack Deutschland y Gascogne c. Unión Europea cit., aptdo. 165; y 6.000 euros para la empresa recurrente en la S. Kendrion c. Unión Europea cit., aptdo. 135.

(74) Se trata de la Sentencia Aalberts Industries c. Unión Europea, de 1 de febrero de 2015, T-725/14.

(75) Sentencia ASPLA y Armando Álvarez c. Unión Europea, de 17 de febrero de 2017,T-40/15.

(76) El incumplimiento del plazo razonable se fija en los mismos veinte meses que en los asuntos Gascogne y Kendrion, puesto que se trataba de asuntos similares (vid. S. ASPLA y Armando Álvarez c. Unión Europea cit., aptdo. 83).

(77) Por un montante de $44.951,24$ euros y $111.042,48$ euros a cada una de las dos empresas afectadas y ahora recurrentes, respectivamente, por los gastos bancarios originados en durante el exceso de duración del proceso, con su correspondiente reevaluación con los intereses compensatorios (vid. S. ASPLA y Armando Álvarez c. Unión Europea cit., aptdos. 153 a 155). Las empresas demandantes no habían solicitado, en este caso, compensación alguna por daños morales.

(78) Sentencia Guardian Europe Sarl c. Unión Europea, de 7 de junio, T-673/15. 
visto desestimado su recurso de casación pero a la que el Tribunal de Justicia le había reconocido la conculcación del plazo razonable durante la tramitación de su recurso de anulación ante el Tribunal General (79). Tras los consabidos óbices procesales planteados por el Tribunal de Justicia de la Unión Europea, el Tribunal General entrará en el fondo de la reclamación patrimonial, reconociendo la violación del art. 47 CDFUE (80) y, en cuanto a las pretensiones indemnizatorias, desestimará la solicitada por daño moral, asumiendo parcialmente la solicitada por daño material (81).

\section{Algunas consideraciones sobre esta nueva vía compensatoria}

La aplicación efectiva de la vía del recurso de indemnización para compensar las dilaciones indebidas sufridas en el Tribunal General suscita diversas reflexiones de interés. Así, con carácter previo, podemos confirmar que la remisión a una vía indemnizatoria autónoma está ya definitivamente asentada y, ahora, experimentada (frente a la vía «endoprocesal» anterior alumbrada en Baustahlgewebe)(82).

La siguiente reflexión es la relativa a la novedad que supone para el ordenamiento de la Unión Europea una solicitud de indemnización basada en un acto ilícito cometido por el Tribunal de Justicia de la Unión Europea, máxime teniendo en cuenta que quien tiene que decidir sobre ello es la propia Institución causante del daño; e incluso, por el sistema de atribución de competencias, en estos casos ya vistos, el propio órgano jurisdiccional al que se le imputa la vulneración del derecho fundamental al plazo razonable.

Pues bien, asumido que así habían de ser las cosas - esto es, que fuera a través de un recurso de indemnización como se articulase la pretensión compensatoria contra la Unión Europea en su conjunto (por ser el sujeto titular, en este caso, de la obligación resarcitoria) -, la siguiente cuestión discutida ha sido quién representaba en un recurso de tales características al sujeto eventualmente responsable del pago.

(79) S. Guardian Industries Corp. c. Comisión cit. supra, en la nota 59.

(80) Por un exceso indebido de 26 meses en la tramitación del citado recurso de anulación (vid. S. Guardian Europe Sarl c. Unión Europea cit., aptdo. 139).

(81) Consistente, como en los casos anteriores, en los gastos bancarios durante el periodo de retraso y cuantificados en $654.523,43$ euros, cantidad que también habrá de reevaluarse con el añadido de los intereses compensatorios (vid. S. Guardian Europe Sarl c. Unión Europea cit., aptdos. 148,165 y 168$)$.

(82) Lo que se reconoce incluso por quien, desde dentro del propio Tribunal de Justicia, prefería la solución inicial (recuérdese la postura del Abogado General Wathelet, recogida supra, en la nota 60$)$. 
El Tribunal de Justicia de la Unión Europea consideraba que no era quien debía asumir tal tarea, sino que le correspondía a la Comisión Europea. Sin embargo, ante tan novedosa cuestión, el Tribunal General encargado de resolver el recurso entendió con firmeza $-y$ en contra del parecer de la propia institución de la que forma parte, hay que insistir (aunque también hay que reconocer que, finalmente, desistió de la vía casacional intentada en un primer momento contra esta interpretación, como sabemos) - que sí debía de ser aquél quien interviniese en el recurso en representación de la Unión. Todo ello sin perjuicio de que la Comisión haya considerado conveniente personarse como coadyuvante de la "otra» institución europea en todos los recursos presentados.

Asimismo, resulta llamativa la actitud procesal del Tribunal de Justicia de la Unión Europea, en su oposición frontal (tanto en el procedimiento como en el fondo) a las demandas de indemnización; sobre todo teniendo en cuenta lo previamente dicho por el Tribunal de Justicia al resolver definitivamente los recursos de casación (en los términos ya vistos). En este sentido, y limitándonos al fondo, hemos visto cómo diversas sentencias de la Gran Sala habían establecido ya, indiscutiblemente, la existencia de una dilaciones indebidas $y$, en consecuencia, la violación del art. 47 CDFUE; $y$, sin embargo, en los posteriores recursos jurisdiccionales el Tribunal de Justicia de la Unión Europea rebatía incluso la existencia misma de tales dilaciones (83).

A esto ha de añadirse un dato adicional, pero también revelador, como es que las cuatro sentencias estimatorias dictadas por el Tribunal General han sido recurridas por el Tribunal de Justicia de la Unión Europea, en recurso de casación, ante el Tribunal de Justicia y están pendientes de resolución (84). Veremos qué resuelve finalmente éste.

Y también es de destacar, por último, que lo que aquí se ha calificado como condicionamientos o advertencias formuladas por el Tribunal de Justicia para que la vía del recurso de indemnización propuesta fuera efectiva $-y$ que podía traslucir una cierta reserva sobre cómo asumiría el Tribunal General el encargo que se le hacía-, se han visto superados

(83) Vid., la S. Gascogne Sack Deutschland y Gascogne c. Unión Europea cit., aptdos. 56 a 58 ; la S. Kendrion c. Unión Europea cit., aptdos. 40 a 43; y la S. Guardian Europe Sarl c. Unión Europea cit., aptdo. 129.

(84) En efecto, el Tribunal de Justicia de la Unión Europea ha planteado recurso contra la S. Gascogne Sack Deutschland y Gascogne c. Unión Europea cit. (as. C-138/17P; si bien es verdad que también lo han hecho, por su parte, las empresas demandantes en la instancia, as. C-146/17P); también contra la S. Kendrion c. Unión Europea cit. (as. C-150/17P); asimismo contra la S. ASPLA y Armando Álvarez c. Unión Europea cit. (as.174/17P; así como la empresa demandante, as. 222/17P); y también contra la S. Guardian Europe Sarl c. Unión Europea cit. (en este caso, de nuevo las dos partes procesales: as. 447/17P y 479/17P). 
por la independencia e imparcialidad (85) con la que se ha tomado todos los recursos la Sala Tercera ampliada de esteTribunal General a la que no le ha temblado el pulso a la hora de condenar al pago como compensación tanto del perjuicio material como del moral ocasionado por sus propias dilaciones indebidas (incluso con cantidades importantes, aunque lógicamente nunca tan elevadas como las solicitadas por las partes perjudicadas).

\section{Una consecuencia de gran alcance: la lesión del derecho fundamental al plazo razonable constituye una violación suficientemente caracterizada del derecho de la Unión Europea a efectos de responsabilidad patrimonial}

Derivar la exigencia de compensación hacia el ejercicio de la acción indemnizatoria y otorgarla efectivamente, en los términos en que se ha hecho, ha producido una consecuencia de mayor alcance que el referido al específico caso que nos ocupa. En efecto, la responsabilidad extracontractual de las Instituciones de la Unión Europea tiene un régimen especifico de carácter restrictivo, asentado desde hace ya muchos años, en el que resulta clave el requisito de que el daño producido lo haya sido por una actuación cualificadamente ilegal: la conocida como "violación suficientemente caracterizada" de una norma del ordenamiento de la Unión Europea, norma que tiene que ser, precisamente, atributiva de derechos a los particulares.

Intentaremos aclarar con mayor precisión los términos de lo que acabamos de recordar para, a continuación, centrarnos en el alcance que tiene la construcción del Tribunal de Justicia referida a la conculcación del derecho fundamental al plazo jurisdiccional razonable. Y, finalmente, nos plantearemos su proyección a todos los derechos fundamentales.

\section{La violación suficientemente caracterizada del Derecho de la Unión como requisito para la indemnización}

Lo que ha hecho, en definitiva, el Tribunal de Justicia en su más reciente interpretación es reconducir al sistema general de la responsabilidad patrimonial extracontractual de las Instituciones de la Unión Europea las pretensiones indemnizatorias por el daño producido por el Tribunal General como consecuencia de su incumplimiento del plazo razonable de enjuiciamiento. Sistema en el que, como es bien sabido, una pieza clave

(85) En este mismo sentido OVÁDEK, M., "At last!...», cit. pág. 443. 
resulta la constatación de la mencionada "violación suficientemente caracterizada del Derecho de la Unión", verdadera conditio sine qua non para tener derecho a la reparación indemnizatoria (86).

Así, esta conocida (87) y nada sencilla exigencia viene a significar que no cualquier infracción del ordenamiento de la Unión generadora de un daño originará la obligación de indemnizarlo, sino sólo aquélla que reúna la mencionada característica, que se hace equivaler a una conculcación manifiesta y grave del Derecho de la Unión Europea(88). Esta construcción es, también, una creación propia y muy específica del Tribunal de Justicia (a partir de su jurisprudencia de los años setenta y, sobre todo, ochenta) - no exenta de autorizadas críticas (89) - , destinada originariamente para los supuestos en los que las Instituciones de la Unión Europea gozan de un margen de apreciación.

Además del ya mencionado carácter de "manifiesto" y "grave», este concepto de violación suficientemente caracterizada no ha sido posteriormente delimitado con mayores precisiones (90), con lo que acarrea, inevitablemente, un gran margen de indeterminación.

(86) Sobre este requisito, ciertamente nuclear en la construcción jurisprudencial de la responsabilidad extracontractual de las Instituciones de la Unión Europea y también de la de los Estados, por el incumplimiento del Derecho de la Unión, valga aquí con la remisión a GUICHOT REINA, E., La responsabilidad extracontractual de los poderes públicos según el Derecho Comunitario. Valencia:Tirant lo blanch, 2001, pp. 230 y ss., 314 y ss. y, sobre todo, 495 y ss. y, más actualizadamente, en "La responsabilidad extracontractual de la Unión Europea», en la obra colectiva dirigida por Beneyto y coordinada por Maillo y Becerril, Tratado de Derecho y Políticas de la Unión Europea. Aranzadi, Cizur Menor, tomo V, 2012, espec. págs. 433 y ss.; y COBREROS MENDAZONA, E., Responsabilidad patrimonial del Estado por incumplimiento del Derecho de la Unión Europea. lustel. Madrid, 2015, espec. págs. 63 y ss.

(87) Puesto que la jurisprudencia delTribunal de Justicia ha venido exigiéndola en el caso de las pretensiones indemnizatorias contra la (entonces) Comunidad, desde hace más de cuatro décadas (así, ya aparece en la Sentencia Zuckerfabrick Schöppenstedt, de 2 de diciembre de 1971, 5/71, aptdo. 11).

(88) Como por el propio Tribunal de Justicia se recuerda en una sentencia emblemática para la responsabilidad extracontractual de los Estados miembros: «sólo incurre en responsabilidad si la institución de que se trata se ha extralimitado, de manera manifiesta y grave, en el ejercicio de sus facultades" (Sentencia Brasserie du Pêcheur y Factortame, de 5 de marzo de 1996, C-6 y 90/93, aptdo. 45).

(89) Como son las de los abogados generales Léger y Tesauro. Así, el primero, en las Conclusiones presentadas el 20 de junio de 1995, en el as. Hedley Lomas, $C-5 / 94$, se hizo favorable eco de las opiniones que consideraban el sistema de la responsabilidad ex 340 TFUE como "insatisfactorio, demasiado riguroso e insuficientemente protector del derecho a un recurso jurisdiccional efectivo" (aptdo. 145, la cursiva en el original).

Por su parte, en las Conclusiones presentadas el 28 de noviembre de 1995 en el asunto Brasserie du Pêcheur y Factortame cit., el Abogado General Tesauro no tendría reparo en decir que "esta jurisprudencia estableció requisitos tan restrictivos, especialmente en relación con la ilegalidad del comportamiento imputable a las Instituciones, que dificulta extraordinariamente la condena de una Institución comunitaria a la indemnización del daño» (aptdo. 63).

(90) A lo más, podrían citarse algunos pronunciamientos en los que el Tribunal General considera cumplido el mencionado requisito cuando se constate "una irregularidad que no habría cometido una administración normalmente prudente y diligente que estuviera en las mismas circunstancias (así, Sentencia Comafrica c. Comisión, de 12 de julio de 2001, T-198/95, 171/96, 230/97, $174 / 98$ y 
Lo que esta (restrictiva) opción interpretativa "pretende, cualquiera que sea la naturaleza del acto ilícito de que se trate, [es] evitar que el riesgo de tener que cargar con las indemnizaciones de los daños alegados por las personas interesadas menoscabe la capacidad de la institución de que se trate de ejercer plenamente sus competencias en vista del interés general, tanto en el marco de su actividad normativa o que implique decisiones de política económica como en la esfera de su competencia administrativa, sin que recaigan sobre terceros, no obstante, las consecuencias de incumplimientos flagrantes e inexcusables» (91). Queda claro, entonces, el motivo que ha llevado al Tribunal de Luxemburgo a introducir este requisito de la cualificación de la ilegalidad cometida por una Institución europea: el interés general ampara la comisión de algún yerro o contravención de la legalidad sin que ello comporte consecuencias indemnizatorias. De tal manera que, siempre que no se supere un determinado umbral de tolerabilidad, el daño producido no será resarcido. Como ha reconocido de manera palmaria el Tribunal General, refiriéndose a una actuación de la Comisión: "la declaración de ilegalidad de un acto jurídico [...] no basta, por lamentable que sea esa ilegalidad, para considerar que concurra el requisito para generar la responsabilidad de la Comunidad» (92).

Claramente y en definitiva, se trata de admitir o reconocer en el ámbito del ordenamiento de la Unión Europea un margen de tolerancia ante determinadas ilegalidades, que conlleva la no resarcibilidad de algunas actuaciones $u$ omisiones dañosas. Tolerancia que es mayor cuando la Institución Europea goza de un margen de discrecionalidad, pero que puede llegar a desaparecer cuando éste no existe.

Más allá del discutible acierto de esta restrictiva interpretación jurisprudencial, conviene resaltar que está muy asentada en el acervo del Tribunal de Luxemburgo, pareciendo inamovible a corto y medio plazo.

225/99, aptdos. 138 y 149; Sentencia Medici Grimm c. Comisión, de 26 de enero de 2006, T-364/03, aptdo. 79; Sentencia Artegodan c. Comisión, de 3 de marzo de 2010, T-429/05, aptdo. 62; y Sentencia Sison III c. Consejo, de 23 de noviembre de 2011, T-341/07, aptdo. 39).

(91) Vid. S. Artegodan c. Comisión cit., aptdo. 55; S. Sison III c. Consejo cit., aptdo. 34; en la Sentencia Animal Trading Company c. Comisión, de 16 de septiembre de 2013, T-333/10, aptdo. 65, Sentencia Safa Nicu Sepahan c. Consejo, de 25 de noviembre de 2014, T-384/11, aptdo. 51; Sentencia Zoofachhandel c. Consejo, de 17 de marzo de 2016, T-817/14, aptdo. 43.

(92) Previamente, el Tribunal se había apoyado en la existencia de sendos recursos, como son el de anulación y el de responsabilidad, que son autónomos y responde a finalidades diferentes. Así, dirá: «En efecto, según la jurisprudencia, el recurso por responsabilidad se estableció como un recurso autónomo, con una función determinada en el marco del sistema de recursos y supeditado a requisitos de ejercicio concebidos en función de su objeto específico (...). Mientras que los recursos de anulación y por omisión persiguen declarar la ilegalidad o la falta de adopción de un acto jurídicamente vinculante, el recurso de indemnización tiene por objeto la solicitud de reparación de un perjuicio causado por un acto o un comportamiento ilícito imputable a una institución". Las citas del texto y de esta nota están tomadas de la $S$. Artegodan c. Comisión cit., aptdos. 49 y 51; reiteradas, para una actuación del Consejo de la Unión Europea, en la S. Sison III c. Consejo cit., aptdos. 31 y 32, respectivamente. 


\section{El incumplimiento del plazo razonable como violación suficientemente caracterizada del Derecho de la Unión Europea}

Volviendo ahora al caso que nos ocupa, ya hemos visto que el Tribunal de Justicia, al reconducir la pretensión compensatoria al recurso de indemnización, ha reconocido explícitamente, y en numerosas ocasiones, que la conculcación del plazo razonable del art. 47 CDFUE constituye una violación suficientemente caracterizada de una norma jurídica que tiene por objeto conferir derechos a los particulares(93).

De la misma manera, al resolver directamente la pretensión indemnizatoria, el Tribunal General también ha deducido la existencia de una violación suficientemente caracterizada -concepto, se insiste, exclusivamente operativo a efectos indemnizatorios - de la nuda conculcación del derecho fundamental al plazo razonable, sin mayores aditamentos o ulteriores condicionamientos (94).

Es Ilamativo que el Tribunal no haya operado, como en otras ocasiones, primero constatando la ilegalidad y, después, analizando si la misma constituye (o no) una violación suficientemente caracterizada, sino que ha dado por presupuesta esta segunda condición una vez producida la lesión del derecho fundamental al plazo razonable. De tal manera que parece deducirse que, superados los márgenes que el "plazo razonable» otorga al órgano jurisdiccional para llevar adelante el proceso, la suficiente caracterización de la violación del Derecho de la Unión se produce automáticamente.

\section{Una (posible) deducción más general: la conculcación de un derecho fundamental constituye per se una violación suficientemente caracterizada del ordenamiento de la Unión}

A) De todas las consideraciones anteriores se podría extraer una más amplia conclusión: la lesión de cualquier derecho fundamental implica una conculcación manifiesta y grave del ordenamiento de la Unión Europea, comprendida, por tanto, en el concepto de "violación suficientemente caracterizada" a efectos resarcitorios.

(93) Vid. la S. Gascogne Sack Deutschland c. Comisión cit., aptdo. 102; la S. Kendrion c. Comisión cit., aptdo. 106; la S. Groupe Gascogne c. Comisión cit., aptdo. 96; la S. Deltafina c. Comisión cit., aptdo. 88; la S. FLS Plast A/S c. Comisión cit., aptdo. 142; la S. ICF c. Comisión cit., aptdo. 59; la S. Galp Energía España c. Comisión cit., aptdo. 57; la S. CEPSA c. Comisión cit., aptdos. 66 y 67; y la S. REPSOL c. Comisión cit., aptdos. 100 y 101.

(94) Vid. la S. Gascogne Sack Deutschland y Gascogne c. Unión Europea cit., aptdo. 78; la S. Kendrion c. Unión Europea cit., aptdo. 63; S. ASPLA y Armando Álvarez c. Unión Europea, cit., aptdo. 83; y la S. Guardian Europe Sarl c. Unión Europea cit., aptdo. 139. 
Ahora bien, debe reconocerse que esta conclusión no resulta ni indiscutible ni indubitada. En efecto, por un lado, tenemos una sentencia un poco anterior en el tiempo del propio Tribunal General que podría interpretarse en sentido diferente. Así, declarada previamente la ilegalidad de un Reglamento, a la hora de resolver una reclamación de indemnización contra la Comisión por los perjuicios imputados a su aplicación, además de la lesión del principio de igualdad -contenida en el Reglamento y constatada por el Tribunal de Justicia (95) - , el Tribunal General indaga si se produjo una violación suficientemente caracterizada, llegando a la conclusión contraria; esto es, había habido una violación del principio de no discriminación, pero ésta no resultó suficientemente caracterizada (96). Como vemos, en este caso de responsabilidad patrimonial de la Unión Europea (por la aplicación de una norma en materia de política pesquera), el Tribunal General ha seguido la pauta más clásica y, tras constatar la ilegalidad - en este supuesto, la conculcación del derecho fundamental a no ser discriminado, del art. 21 CDFUE -, ha analizado si la Comisión había desconocido de manera manifiesta y grave los límites de su facultad de apreciación al adoptar el Reglamento en cuestión y ha concluido que no había sido así. Un planeamiento -a la vista está - diferente del de las sentencias que resolvían sobre las consecuencias dañosas por no respetarse el plazo razonable, en los términos recién vistos.

Además, conviene recordar que sobre esta cuestión aún no se ha pronunciado el Tribunal de Justicia, sino que sólo tenemos resoluciones del Tribunal General.

En cualquier caso, permítase insistir en que no debería ser una tesis - o una propuesta, si se prefiere- demasiado arriesgada sostener que toda lesión de un derecho fundamental constituye (o debería constituir) per se una violación suficientemente caracterizada del ordenamiento de la Unión(97); de tal manera que, cumplidos los demás requisitos, los daños producidos por tal causa siempre deberían resultar indemnizables.

(95) En su Sentencia AJDTuna, de 17 de marzo de 2011, C-221/09, que declaraba injustificada la diferencia de trato entre los diversos sujetos afectados establecida por el Reglamento 530/2008.

(96) Se trata de la Sentencia Pappalardo c. Comisión, de 27 de abril de 2016, T-316/13, aptdo. 40. Debe precisarse que esta Sentencia ha sido desautorizada al recurrirse en casación por la Sentencia Pappalardo c. Comisión, de 13 de septiembre de 2017, C-350/16P, aunque sin incidencia directa en el aspecto que aquí interesa.

Por otra parte, lo dicho en la S. Guardian Europe Sarl c. Unión Europea cit., aptdos. 78 a 126, no resulta de utilidad a nuestros efectos, pese a plantearse en términos similares.

(97) Así me lo permití plantear - siempre con cautelas - inicialmente en COBREROS MENDAZONA, E., "Violación del plazo razonable en el Tribunal de Justicia de la Unión Europea...", cit., págs. 937-939 y posteriormente en Responsabilidad patrimonial del Estado por incumplimiento..., cit., págs. 90 a 92 . 
Otra interpretación diferente nos llevaría a un resultado indeseable (por contrario a la especial posición de que en el ordenamiento de la Unión Europea también gozan los derechos fundamentales), como es admitir la existencia de violaciones de derechos fundamentales que no suponen un incumplimiento grave y manifiesto del Derecho (originario, además) de la Unión Europea, sino algo más leve y tolerable a efectos de no generar indemnización alguna por los daños que produzcan.

Se insiste, de la lógica del sistema y de la propia dicción literal de las sentencias reseñadas parece que deberíamos entender que la lesión de cualquier derecho fundamental recogido en la Carta de Derechos Fundamentales de la Unión Europea supone una violación suficientemente caracterizada a efectos de una eventual acción de indemnización; lo cual no deja de ser una novedosa consecuencia, tanto para el ámbito de protección de los derechos fundamentales como para el de la responsabilidad extracontractual de la Unión.

Pero tampoco podemos dejarnos llevar por nuestras categorías del Derecho público de daños, en donde el ordenamiento español adopta la perspectiva del perjudicado y no la del agente autor de daño. Perspectiva, esta última, que ha sido decisiva en la construcción de la violación suficientemente caracterizada, en la que, precisamente, el punto de gravedad lo constituye la actuación de la Institución Europea y si ésta se ha extralimitado o no de manera grave en su eventual margen de apreciación. No hace falta insistir en la diferencia de óptica entre nuestra tradicional construcción a partir de la antijuridicidad del daño y la de la violación suficientemente caracterizada, razón por la que debemos operar con prudencia y no proyectar nuestras categorías sobre las elaboradas por el Tribunal de Luxemburgo.

B) La propuesta o conclusión anterior, además, debería extenderse a un ámbito más amplio: si la violación de un derecho fundamental por parte de una Institución de la Unión Europea ha de calificarse como una violación suficientemente caracterizada, exactamente lo mismo hay que decir cuando tal violación la origina un Estado miembro, actuando en el ámbito de aplicación del ordenamiento de la Unión Europea, donde también resulta aplicable la Carta (ex art. 51 CDFUE), como es bien conocido.

A estos efectos conviene recordar que el Tribunal de Justicia, modificando su jurisprudencia previa, decidió hace ya más de veinte años que "los requisitos para que exista la responsabilidad del Estado por los daños causados a los particulares por la violación del Derecho comunitario no deben, a falta de justificación específica, diferir de los que rigen la responsabilidad de la Comunidad en circunstancias comparables. En efecto, la protección de los derechos que los particulares deducen del Derecho 
comunitario no puede variar en función de la naturaleza nacional o comunitaria de la autoridad que origina el daño" (98). Esta homogeneización de régimen de la responsabilidad extracontractual por incumplimiento del Derecho de la Unión Europea (99) conllevó, en consecuencia, la incorporación al régimen de la responsabilidad estatal de este requisito de la violación suficientemente caracterizada del Derecho de la Unión Europea que, hasta ese momento, regía sólo para las Instituciones de la (entonces) Comunidad Europea.

E incluso, en nuestro caso, este requisito ha sido asumido - de discutible manera, ciertamente (pero ahora no podemos profundizar en ello)por el legislador básico al regular la responsabilidad patrimonial como consecuencia de la aplicación de una norma incompatible con el Derecho de la Unión Europea [en el art. 32.5,b) LRJSP].

De todo esto lo que aquí interesa es que, si en el ámbito de aplicación del Derecho de la Unión Europea, cualquier órgano de cualquier Estado miembro lesiona un derecho fundamental protegido por la Carta, ello debería constituir también una violación suficientemente caracterizada, a efectos de generar la responsabilidad patrimonial de dicho Estado, sin que éste pueda añadir ningún otro condicionamiento adicional (100).

\section{Conclusiones finales de este largo proceso}

Podemos sintetizar, finalmente, lo visto en todo este recorrido de la siguiente manera.

A) La forma de compensar los perjuicios sufridos por una tramitación jurisdiccional que no ha respetado el derecho fundamental al plazo razonable ha resultado una cuestión debatida en el seno del propio Tribunal de Justicia(101), susceptible de posiciones encontradas entre las partes

(98) S. Brasserie du pêcheur cit., aptdo. 42. Sobre todo ello, puede verse, más ampliamente, COBREROS MENDAZONA, E., Responsabilidad patrimonial del Estado por incumplimiento..., cit., págs. 64 y ss.

(99) Vid., a este respecto, el acertado análisis de GUICHOT REINA, E., La responsabilidad extracontractual de los poderes públicos..., cit., págs. 679 y ss.

(100) Pues la construcción jurisprudencial de la responsabilidad patrimonial de los Estados miembros por incumplimiento del ordenamiento de la Unión (que está fundado en este ordenamiento y no en el de los Estados) tiene el carácter de mínimo, sin que los Estados puedan añadir otros requisitos más gravosos. Lo que viene manteniéndose desde el primer pronunciamiento del Tribunal de Justicia al respecto (vid. su Sentencia Francovich y Bonifaci, de 19 de noviembre de 1991, C-6 y 9/90, aptdo. 41).

(101) Como hemos visto que sucedía en el as. Baustahlgewebe c. Comisión con la posición del Abogado General Léger (vid. supra apartado II.2) y, en sentido contrario, en el as. Guardian Industries Corp. c. Comisión con la posición del Abogado General Wathelet (vid. supra nota 60). 
involucradas (102) y sobre la que el Tribunal de Justicia ha sufrido, en efecto, una evolución interpretativa muy notable.

Hay que tener en cuenta, además, que se trata de una construcción puramente jurisprudencial, ayuna de cualquier referente normativo en el ordenamiento propio y específico de la Unión Europea (aunque, como suele ser habitual, se haya tenido en cuenta alguna referencia tomada de los Derechos de los Estados miembros) y para la que había -como tantas veces sucede a la hora de interpretar y aplicar el Derecho- buenos argumentos jurídicos a favor de una u otra solución; razón por la que tampoco aquí resulta fácil emitir una valoración indubitada.

En efecto, la doctrina Baustahlgewebe o de la satisfacción «endoprocesal» tenía la clara ventaja de la inmediatez a la hora de paliar los perjuicios producidos por un incorrecto funcionamiento jurisdiccional, con lo que la tutela judicial de los intereses del perjudicado resultaba más efectiva, evitándose un nuevo proceso puramente reparatorio, que siempre es una "carga" (en todos los sentidos) para quien lo tiene que instar y una "sobrecarga" para el propio sistema jurisdiccional. Pero tiene también algunos inconvenientes, como son, primero, que sólo sirve para pleitos en los que la sentencia establezca (o ratifique) una obligación cuantificable para el particular perjudicado (más claramente, si es pecuniaria; y siempre a favor de la Unión Europea) y, segundo, que mezcla inevitablemente dos lógicas jurídicas distintas: la de la aplicación de las previsiones normativas para comportamientos infractores (que es la que preside el proceso inicial, en cuyo transcurso se produce, luego, la indebida dilación) y la de la reparación del daño producido en sede jurisdiccional, que es muy distinta.

Sin embargo, la doctrina Gascogne Sack Deutschland o del reenvío a un recurso de indemnización tiene la ventaja de la claridad a la hora de resolver jurídicamente dos cuestiones distintas (separando la de fondo, por un lado, de la reparatoria, por otro) y sirve para todo tipo de procesos (y no sólo aquéllos que finalicen con una sentencia condenatoria "cuantificada»). La pretensión indemnizatoria, así, se sustancia autónomamente con sus propios parámetros, sea cual fuere el proceso en el que se hubiera producido. Pero también conlleva el mencionado inconveniente de que, quien se ha visto perjudicado en la tramitación de un proceso, tiene que iniciar uno nuevo para resarcirse de los perjuicios padecidos en aquél, lo que no deja de retrasar y encarecer el propio mecanismo indemnizatorio.

En cualquier caso, ahora ya sabemos: a) que la vía a transitar en estos supuestos es la del recurso (autónomo) de indemnización; b) que ha de

(102) Prueba de ello la tenemos en lo recogido supra, en la nota 43. 
plantearse contra la Unión Europea (que es quien tiene la personalidad jurídica ex art. 47 TUE), representada por la Institución Tribunal de Justicia de la Unión Europea (que es la causante del daño); y c) que dicho recurso debe resolverse por el Tribunal General (que es quien tiene atribuida la competencia para su conocimiento ex art. 256.1 TFUE), pero que deberá hacerlo en una formación diferente de la que conoció del litigio en el que no se respetó el plazo razonable, si es a dicho órgano jurisdiccional a quien se le reprocha el indebido retraso (como han sido todos los casos planteados) (103).

B) Esta última consideración nos permite avanzar una reflexión más amplia y plantear la cuestión en relación con el respeto a ese mismo derecho fundamental del que estamos hablando, pero para el supuesto de una tramitación litigiosa seguida ante el Tribunal de Justicia.

En efecto, como es bien sabido, los derechos fundamentales protegidos en la Carta vinculan a todas las Instituciones de la Unión Europea (art. 51.1 CDFUE), entre las que se encuentra el Tribunal de Justica de la Unión Europea (que comprende el Tribunal de Justicia y el Tribunal General). Pero es que, además de por el art. 47 de la Carta, ese mismo derecho al plazo razonable le vincula por la vía (indirecta, si se quiere) del art. 6.1 CEDH (104), puesto que, para la debida interpretación de este último precepto, tenemos que tener en cuenta lo dicho por el Tribunal de Estrasburgo. Y este Tribunal ha considerado aplicable la exigencia del plazo razonable no sólo para las más altas instancias judiciales nacionales

(103) A diferencia de lo que sucede en el sistema de la Unión Europea, entre nosotros las reclamaciones de los daños causados por un proceso judicial que haya incurrido en dilaciones indebidas - que es, por cierto, el prototipo de funcionamiento anormal de la Administración de Justicia ( $v i d$. COBREROS MENDAZONA, E., "Funcionamiento anormal de la Administración de Justicia e indemnización", en RAP núm. 177, 2008, espec. págs. 42 y ss.) - no se tramitan como una acción judicial directa, sino a través del procedimiento administrativo previsto en el art. 293.2 LOPJ (que, a su vez, nos remite a la Ley del Procedimiento Administrativo Común), esto es como una reclamación administrativa ante el Ministerio de Justicia, con posterior revisión, en su caso, por la Jurisdicción Contencioso-Administrativa. Sin embargo, la declaración de error judicial -que es el otro título de imputación previsto en el art. 121.1 CE para que la indemnización corra a cargo del Estado - sí que se ejercita directamente ante el Tribunal Supremo (como requisito previo inexcusable para solicitar luego la indemnización al Ministerio de Justicia, según establece el art. 293 LOPJ), y en este caso sí que se prevé que, si el error judicial se imputase a una resolución judicial proveniente de alguna Sala o Sección del propio Tribunal Supremo, la competencia para declarar dicho error judicial corresponderá a la Sala del art. 61 de la Ley Orgánica del Poder Judicial.

(104) Ya que el art. 52.3 CDFUE establece que los derechos contenidos en ésta que correspondan a derechos garantizados por el Convenio Europeo de los Derechos Humanos tienen el mismo sentido y alcance que los que le confiere dicho Convenio. Si bien es cierto que éste no constituye un instrumento jurídico integrado formalmente en el ordenamiento de la Unión Europea, porque ésta no se ha adherido a dicho Convenio (así, desde la Sentencia Akerberg Fransson, de 26 de febrero de 2013, C-617/10 aptdo. 44). Ya hemos visto que, desde el principio, el propio Tribunal de Justicia mencionaba ambos soportes normativos para resolver esta cuestión (vid. lo dicho en supra en el apartado II.3, en relación con la $S$. Baustahlgewebe c. Comisión). 
ordinarias, sino también, expresamente, para los tribunales constitucionales de los Estados (105).

En fin, cuando se haga efectiva la prevista ratificación del Convenio Europeo de Derechos Humanos por parte de la Unión Europea, con el correspondiente sometimiento a la jurisdicción del Tribunal Europeo de Derechos Humanos - aunque no sea una circunstancia previsible a corto plazo, como es unánimemente advertido-, por un lado, éste garantizará en última instancia el respeto al derecho fundamental al plazo razonable, en todas las actuaciones judiciales en el seno de la Unión Europea; y, por otro lado, la Unión Europea tendrá que tener también en su seno un "recurso efectivo" (del art. $13 \mathrm{CEDH}$ ) para estos supuestos de eventual lesión del plazo razonable garantizado por el art. 6.1 $\mathrm{CEDH}$, a cuyos efectos la construcción Gascogne Sack Deutschalnd le puede venir muy bien(106).

La hipótesis no es, en absoluto, descabellada, porque bien pudiera ocurrir que un interesado considere que ha existido una violación del plazo razonable en la tramitación de su recurso de casación contra una sentencia previa delTribunal General, por ejemplo, y decida obtener la reparación de los daños que le ha causado. En este supuesto, el perjudicado podría intentar una acción de indemnización ante el Tribunal General; con lo que éste, tendría que analizar, primero, si se ha producido una lesión del plazo razonable por parte del Tribunal de Justicia y, luego, los restantes elementos para la obtención de la indemnización.

Es más, rizando el rizo de las oportunidades procesales, también podría suceder que, ante la desestimación de tal pretensión indemnizatoria por parte del Tribunal General, la parte recurrente se alzara en casación ante el Tribunal de Justicia, que - aplicando su propia doctrina- parece que debería conocer de este recurso en una formación distinta de aquélla que tramitó el primitivo recurso (objeto, ahora, de discusión a efectos resarcitorios).

Sobre esta posibilidad(107) el Tribunal de Justicia no ha adelantado nada, aunque sí tenemos una reciente reflexión del Tribunal General, que, tras afirmar - de manera bien novedosa, por cierto; ya que, salvo error, es

(105) Así, el caso más reciente de aplicación de la exigencia del plazo razonable a una jurisdicción constitucional lo tenemos en la STEDH de 28 de junio de 2016, as. Cicmanec c. Eslovaquia, núm. 65302/11. Para conocer la evolución interpretativa seguida por el Tribunal de Estrasburgo sobre esta materia - desde su inicial interpretación reacia a incluir a los tribunales constitucionales en el ámbito de aplicación de este art. 6.1 CEDH (vid. la STEDH de 6 de mayo de 1981, as. Buchholz c. Alemania, núm. 7745/77) - puede verse COBREROS MENDAZONA, E., "La violación del “plazo razonable" por la Jurisdicción Constitucional», en Repertorio Aranzadi delTribunal Constitucional, núm. 16, 2002 , págs. 13 y ss.; y, posteriormente, en «El difícil problema de la responsabilidad patrimonial por funcionamiento anormal delTribunal Constitucional", en RVAP, núm. 87-88, 2010, págs. 297 y ss.

(106) Recuérdese lo recogido supra, en la nota 3.

(107) Que también me aventuré a formular en COBREROS MENDAZONA, E., "Violación del plazo razonable en elTribunal de Justicia de la Unión Europea...", cit., pág. 940. 
la primera vez que se formula en sede luxemburguesa tal hipótesis - que "no se genera la responsabilidad de la Unión por el contenido de una resolución judicial que no ha sido dictada por un órgano jurisdiccional de la Unión que resuelve en última instancia y que, en consecuencia, era recurrible en casación»(108), añade que esto debe entenderse "sin perjuicio de la posibilidad de que una parte demandante exija, en casos excepcionales, responsabilidad a la Unión como consecuencia de anomalías de funcionamiento jurisdiccionales graves, en particular de índole procesal o administrativa, que afecten a la actividad de un órgano jurisdiccional de la Unión» (109). Como se ve, de esta posibilidad no se excluye, en absoluto - más bien se deduce lo contrario-, la hipótesis (si bien excepcional) de una indemnización por causa del incumplimiento del plazo razonable por parte delTribunal de Justicia.

C) Por último - como ya se ha remarcado suficientemente en el apartado anterior - , la construcción jurisprudencial de la reparación del daño en caso de incumplimiento del plazo razonable ha desvelado una nueva posible consecuencia en los casos de lesión de un derecho fundamental garantizado por la Carta de Derechos Fundamentales de la Unión Europea, cual es que debería constituir una violación suficientemente caracterizada, a efectos indemnizatorios. Lo que confirmaría y robustecería la posición preferente de éstos en el ordenamiento de la Unión, significando una garantía añadida para los particulares perjudicados (la patrimonial), tanto ante las Instituciones de la Unión Europea como ante los Estados miembros.

Pero esto - conviene insistir en la cautela - aún no lo ha dicho así el Tribunal de Justicia.

Trabajo recibido el 12 de septiembre de 2017

Aceptado por el Consejo de Redacción el 20 de octubre de 2017

(108) S. Guardian Europe Sarl c. Unión Europea cit., aptdo. 122. Lo que, trasladado a nuestras categorías internas, sería un trasunto del requisito establecido en el art. 293.1,f) LOPJ para la declaración del error judicial indemnizable (ex art. $121 \mathrm{CE}$ ).

(109) Ibídem, aptdo. 124 (la cursiva está añadida). 
LABURPENA: Zentzuzko epea funtsezko eskubidea da Europar Batasunaren ordenamenduan. Askotan eztabaidatu da eskubide hori urratzeak eragin ahal izan dituen kalteak konpentsatzeko moduaren gainean, eta Justizia Auzitegiaren interpretazioa eboluzionatuz joan da. Horren inguruko azken jarreraren ondorioz, kalte-ordaina emateko errekurtsoa abiarazi behar da Auzitegi Nagusiaren aurrean, konpentsazioa jaso nahi bada. Ondorio berri bat ekar dezake horrek Europar Batasunaren kontratuz kanpoko erantzukizun-sisteman; hau da, oinarrizko eskubide bat kaltetzeak per se ekar lezake behar beste ezaugarritutako urraketa egotea. Horrek indartu egingo luke oinarrizko eskubideek lehentasunezko kokalekua edukitzea Europar Batasunaren ordenamenduan.

GAKO HITZAK: Zentzuzko epea. Luzamendu desegokiak Europar Batasuneko Justizia Auzitegian. Europar Batasuneko kontratuz kanpoko erantzukizuna. Funtsezko eskubide bat urratzea eta Batasuneko zuzenbidearen urraketa nahikoa karakterizatua.

RESUMEN: El plazo razonable es en la actualidad un derecho fundamental en el ordenamiento de la Unión Europea. La compensación de los daños que pudiera haber producido su conculcación ha sido una cuestión debatida y en la que la interpretación delTribunal de Justicia ha experimentado una clara evolución. La última postura al respecto obliga a iniciar un recurso de indemnización ante el Tribunal General para obtenerla. Ello plantea una posible consecuencia novedosa en el sistema de responsabilidad extracontractual de la Unión Europea, como es que la lesión de un derecho fundamental podría constituir per se una violación suficientemente caracterizada, lo que reforzaría la posición preferente de los derechos fundamentales en el ordenamiento de la Unión Europea.

PALABRAS CLAVE: Plazo razonable. Dilaciones indebidas en elTribunal de Justicia de la Unión Europea. Responsabilidad extracontractual de la Unión Europea. Lesión de un derecho fundamental y violación suficientemente caracterizada del Derecho de la Unión.

ABSTRACT: Reasonable period of time is currently a fundamental right in the EU legal order. The compensation of damages that might have been caused by its infringement is a discussed matter and there the interpretation provided by the Court of Justice has experienced a clear evolution. The last position on this matter calls for filing an action for damages before the General Court in order to obtain a compensation. This raises a possible new consequence within the legal regime of the non contractual liability of the European Union, that is that the impairment of a fundamental right might be considered per se as a sufficiently serious breach which would strengthen the prevalent position of fundamental rights in the legal order of the European Union.

KEYWORDS: Reasonable time. Undue delay in the Court of Justice of the European Union. Non contractual liability in the European Union. Impairment of a fundamental right and sufficiently serious breach of the EU Law. 